DEVELOPMENT OF LEAD-FREE

COPPER ALLOY-GRAPHITE CASTING

Annual Technical Progress Report

By.

P. K. Rohatgl

February 1996

Work Performed Under Contract DE-FC07-931D13236

For

U.S. Department of Energy

Assistant Secretary for

Energy Efflciency and Renewable Energy

Washington, D.C.

By

Universtty of Wisconsin - Milwaukee

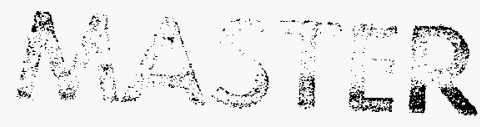




\section{DISCLAIMER}

This report was prepared as an account of work sponsored by an agency of the United States Government. Neither the United States Government nor any agency thereof. nor any of their employees, makes any warranty, express or implied, or assumes any legal liability or responsibility for the accuracy, completeness, or usefuiness of any information, apparatus, product, or process disclosed, or represents that its use would not infringe privately owned rights. Reference herein to any specific commercial product, process, or service by trade name, rademark, manufacturer, or otherwise does not necessarily constitute or imply its endorsement. recommendation, or favoring by the United States Govemment or any agency thereof. The views and opinions of authors expressed herein do not necessarily state or reflect those of the United States Government or any agency thereof.

This report has been reproduced directly from the best available copy.

Available to DOE and DOE contractors from the Office of Scientific and Technical Information, P.O. Box 62, Oak Ridge, TN 37831; prices available from (615) 576-8401.

Available to the public from the U.S. Department of Commerce, Technology Administration, National Technical Information Service, Springfield, VA 22161, (703) $487-4650$. 


\section{DISCLAIMER}

Portions of this document may be illegible in electronic image products. Images are produced from the best available original document. 
DOE/ID/13236-1

(DE96005615)

Distribution Category UC-1420

\title{
DEVELOPMENT OF LEAD-FREE COPPER ALLOY-GRAPHITE CASTING
}

\author{
Annual Technical \\ Progress Report
}

By

P. K. Rohatgi

February 1996

Work Performed Under Contract No. DE-FC07-93ID13236

For

U.S. Department of Energy

Under DOE Idaho Operations Office Sponsored by the Office of the Assistant Secretary

for Energy Efficiency and Renewable Energy

Office of Industrial Technologies

Washington, D.C.

By

University of Wisconsin - Milwaukee Milwaukee, Wisconsin 53201 


\section{ABSTRACT}

Water model experiments were conducted to develop a two-stage stirring method for obtaining higher yields and a more uniform distribution of particles in copper alloys. This was followed by several melts for synthesis of copper-graphite alloys in which $\mathrm{Ti}$ was used as a wetting agent to improve the wettability of graphite in the copper melt. In the first stage, a vortex method was employed to facilitate the suction of graphite particles into the copper melt. In the second stage, the specially designed stirrer was used to avoid the formation of vortex in the melt. The two stage stirring was found to considerably improve the recovery of graphite, over those obtained with the prior practice of single stage stirring. In addition, graphite recoveries increased with increasing $\mathrm{Ti}$ content.

Floatation, fluidity, and directional solidification experiments were also conducted on copper-graphite alloys synthesized in this study. Fluidity tests showed that the spiral fluidity length of the yellow brass alloy increased with temperature and decreased with graphite. The fluidity of copper-graphite alloys investigated to date remained adequate to make a variety of castings. The observations of microstructure of directional solidification and floatation showed that in certain castings the graphite particles were agglomerated and they float to the upper part of the castings where they reduced the size of grains. However, even in the agglomerated form, the graphite particles improved the machinability of copper alloys in a manner similar to lead. The result of the first years work provide an improved method of synthesis of lead free copper graphite alloys with improved machinability and adequate fluidity. Future work will continue to further improve the distribution of graphite particles in casting while retaining adequate fluidity and improved machinability. Techniques like centrifugal casting will be developed to concentrate graphite in regions where it is required for machinability in bearings. 
$-$ 


\section{TABLE OF CONTENTS}

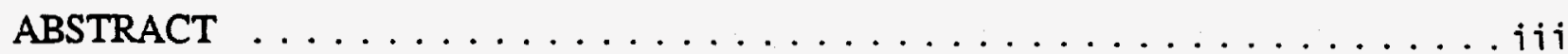

TABLE OF CONTENTS $\ldots \ldots \ldots \ldots \ldots \ldots \ldots$

LIST OF FIGURES $\ldots \ldots \ldots \ldots \ldots \ldots \ldots \ldots \ldots \ldots \ldots \ldots$

LIST OF TABLES $\ldots \ldots \ldots \ldots \ldots \ldots \ldots \ldots \ldots \ldots \ldots \ldots \ldots \ldots$

1. INTRODUCTION $\ldots \ldots \ldots \ldots \ldots \ldots \ldots \ldots \ldots \ldots \ldots \ldots \ldots \ldots$

2. OBJECTIVES AND WORKSCOPE $\ldots \ldots \ldots \ldots \ldots \ldots \ldots \ldots \ldots$

3. TECHNICAL WORK $\ldots \ldots \ldots \ldots \ldots \ldots \ldots \ldots \ldots \ldots \ldots \ldots \ldots \ldots$

3.1 Lead Substitution with Graphite $\ldots \ldots \ldots \ldots \ldots \ldots \ldots$

3.2 Technical Challenges in Copper Alloy Graphite Composite Development . . . . 3

3.2.1 Wetting of Graphite by Copper Melt . . . . . . . . . . . 3

3.2.2 Addition of Graphite to the Copper Melt: The Vortex Method . . . . . . 5

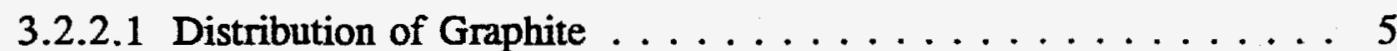

3.2.2.2 Floatation of Graphite Particles . . . . . . . . . . . 6

3.2.2.3 Some Fundamental Aspects of Liquid Metal Transport Phenomena 7

3.3 Experimental Results and Discussion $\ldots \ldots \ldots \ldots \ldots \ldots$

3.3.1 Vortex and Bubble Formation Studies in Water . . . . . . . . . 9

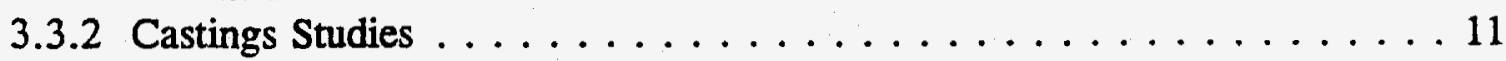

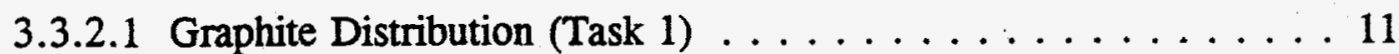

3.3.2.2 Fluidity Studies (Task 2) $\ldots \ldots \ldots \ldots \ldots \ldots \ldots \ldots \ldots$

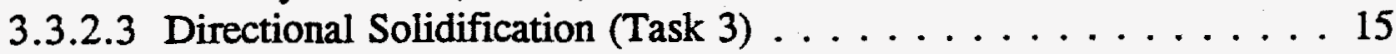

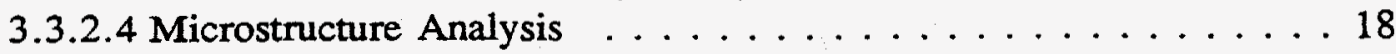

3.3.2.5 Floatation . . . . . . . . . . . . . . . 19

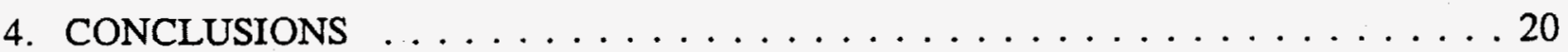

5. RECOMMENDATION AND FUTURE WORK $\ldots \ldots \ldots \ldots \ldots \ldots \ldots$

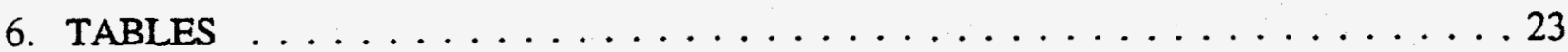

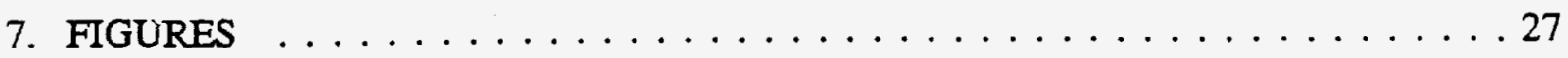




\section{LIST OF FIGURES}

Fig. 1. Bubble and vortex formation when 90 degree bladès are used to stir water at different speeds. . . . . . . . . . . . . . . $\mathbb{Z}$

Fig. 2. Bubble and vortex formation when 60 degree blades are used to stir water at different speeds. . . . . . . . . . . . . . . 28

Fig. 3. Bubble and vortex formation when 45 degree blades are used to stir water at different speeds.

Fig. 4. Chemical analysis of carbon along the length of 1 in diameter rod

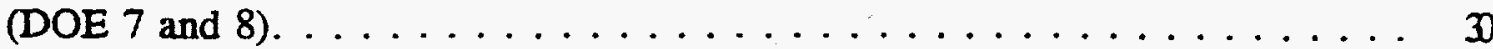

Fig. 5. Chemical analysis of carbon along the length of 1 in diameter rod (DOE 9 and 10).

Fig. 6. Variation in graphite percentage in the composite castings when stirred in one stage and in two stages. . . . . . . . . . . . . .

Fig. 7. Improvement in graphite recovery due to two stage stirring: this may permit lower amounts of titanium required. $\ldots \ldots \ldots \ldots \ldots \ldots \ldots$

Fig. 8. Locations from which samples were taken for metallographic examination. . . 34

Fig. 9. The fluidity of yellow brass and copper-graphite composites slurry, variation of fluidity with different graphite contents. The $\mathrm{C} 90300$ castings contained $1.5 \% \mathrm{Ti}$, others had no Ti. . . . . . . . . . . . . . . . . . .

Fig. 10. Schematic illustration of the directional solidification experimental setup. . . . $\mathfrak{Z}$

Fig. 11. Typical cooling curves of $\mathrm{C} 90300$ of copper alloy-graphite composite in directional solidification experiments. The thermocouples are located neat the bottom (a), and central and upper (b) parts of the mold. . . . . . . . . . 3

Fig. 12. Variation of cooling rate with casting height; location of thermocouples are shown

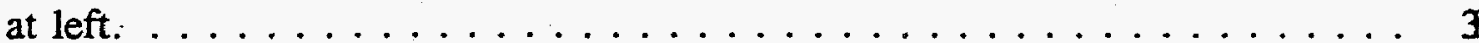

Fig. 13. Structure of the copper-graphite castings after directional solidification. (a) bottom

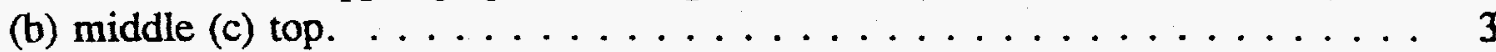

Fig. 14. Photomicrographs of fluidity spiral of yellow brass-1.5 wt \% graphite composite $1 \mathrm{wt} . \% \mathrm{Ti}$, showing distribution of graphite $\ldots \ldots \ldots \ldots$ 
Fig. 15. Photomicrographs of fluidity spiral of yellow brass $-1.5 \mathrm{wt} . \%, 1 \mathrm{wt} \% \mathrm{Ti}$, graphite composite showing distribution of graphite. . . . . . . . . . . . 4

Fig. 16. Photomicrographs of fluidity spiral of yellow brass-1.5 wt $\%$ graphite, -1 wt $\%$ Ti composite, showing graphite particle distribution and titanium carbide phase around graphite particles. ..................... 4

Fig. 17. Variation of dendrite arm spacing of yellow brass matrix at different locations of casting spiral of composites. .................

Fig. 18 Macrograph of the copper alloy-graphite casting without any isothermal holding at $1000^{\circ} \mathrm{C}$ (i.e., zero holding time) $\ldots \ldots \ldots \ldots \ldots$

Fig. 19 Macrograph of the copper alloy-graphite casting after 10 minutes of isothermal holding

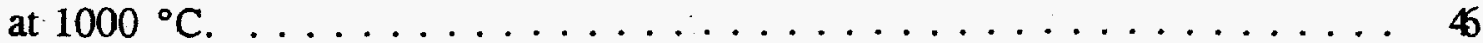

Fig. 20 The relative floatation height in the yellow brass-graphite composite as a function of composite-melt holding time. 


\section{LIST OF TABLES}

Table 1. Experiments to Optimize Wetting Agent Addition $\ldots \ldots \ldots \ldots$

Table 2. An Analysis of Two Castings for Repeatability ............. 24

Table 3. Some Observations on Table 2 Data $\ldots \ldots \ldots \ldots \ldots \ldots$

Table 4. Yellow Brass-Graphite Composite Fluidity-Spiral Evaluation . . . . . . 26 


\section{ACKNOWLEDGEMENTS}

The continued scientific interaction of Mr. R. Timberger and Dr. M. Sohal of DOE in this work has been very valuable. The help of Kohler Co., Johnson Controls, Colonial Metals, Superior Graphite Co., Bunting Bearing, Copper Development Association, International Copper Research Association, Grandhaven Foundry and Starline Manufacturing is acknowledged. 


\section{INTRODUCTION}

This report summarizes the work undertaken by UWM Foundry Laboratory under DOE project entitled "Development of Lead-Free Copper Alloy-Graphite Castings". Leaded copper alloys are mainly used for plumbing and bearing applications. However, leaching of lead into drinking water from plumbing components has health hazards. In addition, lead particles and fumes released to the atmosphere during processing of lead containing copper alloys are also a health hazard. Accordingly, the substitution of lead in brass plumbing components is of great importance.

In this study, graphite is used as a substitute for lead in order to maintain the machinability of plumbing components at the level of leaded brass. Since graphite is not wetted by molten copper alloys, titanium was used as a wetting agent to improve the wettability of graphite in the copper melt. Chromium is also known as a good wetting agent for graphite. However, since the $\mathrm{Cr}_{3} \mathrm{C}_{2}$ is harder than $\mathrm{TiC}$, titanium was selected as a wetting agent for the initial work. Model experiments were conducted to develop a two-stage stirring technique for obtaining higher recoveries and a uniform distribution of particles in the composite castings. In the first stage stirring, a vortex technique was employed to facilitate the suction of graphite particles into the much denser melt of copper alloys. In the second stage, the graphite particles incorporated in the copper alloy melts were uniformly distributed and stabilized avoiding vortex formation in the melt. The flow behavior of copper alloys containing graphite particles in narrow channels was studied by fluidity tests. The effect of the cooling rate on graphite particle distribution was determined to design optimum molds for copper alloys containing graphite particles. Also, the

floatation behavior of graphite particles in the copper melt was quantified to understand the permissible holding times for molten alloys in the furnace, or during ladle transfer and castings. 


\section{OBJECTIVES AND WORKSCOPE}

Lead containing copper alloys are widely used in plumbing applications for their high machinability and easy castability. Lead as discrete soft dispersoids in copper alloy matrix improves machinability of the plumbing components. It does not form a film along grain boundaries, as does bismuth, and is this not harmful to mechanical properties. However, during processing, specially in foundries, personnel may be exposed to lead emissions. Health and safety problems associated with the manufacture and the use of lead-containing alloys are not restricted to foundry workers. When used as plumbing components, small amounts of lead tends to leach into water exposing consumers to lead ingestion which can cause health problems. Hence, the development of lead-free alloys with good machinability is needed for plumbing applications. Complete elimination of lead in copper alloys will enhance the environmental performance of the foundries and help them in meeting the standard environmental regulations.

To solve the above problems, the University of Wisconsin-Milwaukee has explored the use of graphite which was found to impart adequate machinability in copper alloys, as it does to cast irons. Based on initial results, graphite was found to impart significant machinability to copper alloys, when properly distributed. Graphite is also found to be acceptable for piumbing applications from the standpoint of inertness, platability and corrosion resistance.

The project was started on January 1, 1994. In the first year of the program, primary efforts have been directed towards:

1. Developing techniques for managing distribution of graphite

2. Studies on casting characteristics of copper alloys containing dispersed graphite

3. Directional solidification and microstructural studies

4. Characterization of selected properties of copper alloys containing dispersed graphite. 


\section{TECHNICAL WORK}

\subsection{Lead Substitution with Graphite}

Plumbing copper alloy components contain lead to enhance their machinability. The soft particles of lead are distributed as discrete units in the metal matrix. These discrete particles of lead in the matrix of copper alloys result in breaking of chips during machining. In addition, lead particles appear to provide some lubrication to the tool surface.

The experimental results obtained at UWM showed that graphite dispersed in $\mathrm{Cu}$ alloy imparts a good machinability as graphite does to cast iron. Graphite reduces the sizes of chips during machining of plumbing components in a manner similar to lead.. Thus graphite can be expected to be a suitable substitute for lead in cast plumbing components. Also, graphite is known to have good lubrication properties.

\subsection{Technical Challenges in Copper Alloy Graphite Composite Development}

Several technical problems have to be solved before acceptable cast copper alloy-graphite composite components can be developed. Some of the major problems are (1) adequate wetting of graphite by the copper alloy, (2) introduction of lighter graphite particles into the high density copper melt, (3) uniform distribution and complete deagglomeration of graphite particles in the melt, and (4) prevention of floatation of graphite from the melt. These problems have been encountered in this study and steps taken to overcome these problems in the synthesis and casting of copper-graphite alloys.

\subsubsection{Wetting of Graphite by Copper Melt}

Surface tension of liquid alloys significantly controls the ease with which particles are introduced in the liquid melt. The lower the surface energy, the easier it is to introduce the 
particles. This is basically governed by the Young Dupre equation which explains the relationship between various surface energies and wettability of particles by liquid alloys. Graphite has a high surface energy and it does not wet copper alloy. This is also indicated by a contact angle of the order of 140 degrees between molten copper alloys and graphite. This indicates that graphite will be very difficult to introduce into the melt of copper alloys. To improve surface wetting of graphite particles, selected wetting agents may be added to the melt in small quantities. This improvement in wetting is caused by the adsorption of the added alloying atoms on the metal-particle interface or chemical reaction on the surface of graphite. Particularly, titanium and chromium at higher levels of $5-6 \%$ bring down the contact angle to the limiting condition of zero degrees, i.e., under this condition, copper completely wets graphite. In addition to the amount of alloying elements, the temperature of the liquid and the duration of contact between the liquid copper and substrate influence the contact angle. For example, at higher operating temperatures, the amount of alloying elements required to decrease the contact angle is relatively low. Also, a longer time of contact gives a lower wetting angle. All these factors were evaluated in our study.

Summarizing, pure copper and typical copper alloy melts do not wet graphite, but the surface tension of pure copper decreases with an increase in the melt temperature. Also, the presence of oxygen content in the melt increases the surface tension with an increase in temperature. The addition of certain elements helps in decreasing the contact angle between copper and graphite substrates. Amongst the various elements, titanium and chromium appear to be very effective alloys. In this study, titanium was used as a wetting agent. 


\subsubsection{Addition of Graphite to the Copper Melt: The Vortex Method}

A wide range of particulate reinforced metal matrix composite have been successfully produced by means of liquid metallurgy and casting technique. As the first step, particles must be fully incorporated in the meit. However, since the density of a copper melt is much higher than that of graphite, graphite particles can not be easily introduced into the copper melt without an external force. One of the methods of introducing graphite particles into a copper melt is the vortex technique. The negative pressure at the center part of a vortex helps in sucking graphite particles into the copper melt. Accordingly, in our experiments the stirrer was designed to create a vortex in the melt so that fluid inertia and centrifugal forces are directed downward to draw in and force the lighter graphite particles into the higher density melt. A higher vortex is necessary because of the four-fold difference between the densities of graphite $(2.2 \mathrm{~g} / \mathrm{cc})$ and the molten copper alloy $(8.0 \mathrm{~g} / \mathrm{cc})$.

\subsubsection{Distribution of Graphite}

Once introduced into the melt, the distribution of graphite particles determines the quality of castings. If graphite particles are not homogeneously distributed in the copper melt, the volume fraction of graphite will vary from point to point in the melt, as well as in the solidified metal. The agglomerated clusters of graphite particles in the melt during mixing will amplify the buoyancy effect and floatation will take place at a much faster rate. On the other hand, the clustering of graphite particles before graphite addition into the copper melt influences the distribution of graphite particles in the copper melt or castings. Even though graphite particles are dried before their addition to the melt, fine graphite particles tend to remain agglomerated resulting in the floatation of particles at a much higher velocity in the copper melt. In addition, the formation of bubbles created during mixing enhances the floatation of graphite particles 
because graphite particles tend to attach to bubble surfaces. Accordingly, in our experiments, the stirrer blades for graphite distribution were designed so that no vortex is created and bubble generation is drastically minimized. The stirrer is required to vigorously stir the melt with the added particulate and to break up any small clusters of graphite particles so that individual particles are fully wetted by the melt and distributed spatially in a uniform manner and thus avoid the formation of bubbles which lead to enhancement of floatation of graphite particles. Other techniques of deagglomeration of the as-received particles prior to addition to the melt are also under development. During solidification, the interaction with the growing dendrite crystal grains influences the distribution of graphite particles by pushing them into the interdendritic regions resulting in a nonuniform distribution of graphite particles.

\subsubsection{Floatation of Graphite Particles}

Graphite particles added into the copper melt tend to float due to the lower density of the graphite particles than of the copper melt. The floatation velocity of graphite particles in the copper melt depends on particle sizes, their relative densities, and melt viscosity which is a function of melt temperature, as well as the volume fraction of the particles. Stoke's law allows one to make a first order estimate of the floatation velocity. At large particle concentrations, some interaction with existing particles may cause a decrease in the velocity, and this "hindered" floatation velocity can be calculated using the melt viscosity modified by the added particle volume fraction. The hindered floatation velocities of 5 and $10 \mu \mathrm{m}$ diameter spherical graphite particles in a copper melt at $5 \mathrm{vol} \%$ are $1.8 \mathrm{~mm} / \mathrm{s}$ and $7.3 \mathrm{~mm} / \mathrm{s}$, respectively. If ingot solidification time is 10 seconds, these graphite particles may float up by 18 to $73 \mathrm{~mm}$. In fluidity spirals experiments, solidification times are of the order of 0.5 seconds and only a few millimeter floatation is likely to occur. In our experiments flake shape graphite particles were 
used to reduce the veloctiy of floatation compared to these values calculated for spherical particles. To obtain castings with a good distribution of graphite particles, the solidification of composite castings must be rapid enough to minimize floatation of graphite particles and the proper size of mould must be used. Since the floatation velocity of graphite particles is a function of size and volume fraction of graphite particles, the finer graphite particles help in reducing the floatation of graphite particles at given volume fractions of graphite particles. In addition to improving the distribution of particles, the clustering of particles during mixing in the copper melt must be completely avoided to minimize rapid floatation of graphite particles. Therefore, it is important to design a stirrer which generates a high shear flow to separate the clusters of particles in the melt. Also, prior treatment of as-received particles to deagglomerate them is being actively pursued.

In addition, the addition of elements such as titanium and chromium helps in wetting of the graphite particles by the copper melt. The surface chemical reaction between elements and graphite particles increases the density of graphite particles resulting in a reduction in the floatation velocity. In particular, adding elements changes the wettability between the copper melt and graphite particles resulting in an increased drag force acting between the graphite particles and the copper melt. This causes the floatation of particles to be further lowered.

\subsubsection{Some Fundamental Aspects of Liquid Metal Transport Phenomena}

It is recognized that an adequate understanding of the several forces governing the floatation of particles in a stable composite melt during stirring and progressive solidification will be of assistance to the empirical efforts in composite melt technology development. Some of the important forces are: buoyancy, viscous drag, inertia, gravity, surface tension, and centrifugal. 
Various grouping of these forces can be made to obtain dimensionless numbers which may be very helpful in systems analysis of many composite-melts, e.g., $\mathrm{Cu}$ alloy-graphite, Al-graphite, Al-flyash, $\mathrm{Al}-\mathrm{SiC}, \mathrm{Al}-\mathrm{Al}_{2} \mathrm{O}_{3}, \mathrm{~Pb}$-flyash, etc. Typical force groupings are indicated below:

1. Stokes $=\frac{\text { Viscous Force }}{\text { Gravity Force }}=\frac{\mu \mathrm{V}}{\rho \mathrm{g} \ell^{3}}$

2. Buoyancy $=\frac{\text { Buoyant Force }}{\text { Viscous Force }}=\frac{\ell^{2} w \beta \Delta t}{\mu \mathrm{XV}}$

3. Reynolds $=\frac{\text { Inertia Force }}{\text { Viscous Force }}=\frac{\mathrm{V}^{2}}{\mu}$

4. Froude $=\frac{\text { Inertia Force }}{\text { Gravity Force }}=\frac{\mathrm{V}^{2}}{\mathrm{~g} \ell}$

5. Gallileo $=\frac{\text { Gravity Force }}{\text { Viscous Force }}=\frac{\mathrm{g} \ell^{3} \rho^{2}}{\mu^{2}}$

6. Capillary $=\frac{\text { Viscous Force }}{\text { Surface Tension Force }}=\frac{\mu \mathrm{V}}{\sigma_{\mathrm{t}}}$

7. Taylor $=\frac{\text { Centrifugal Force }}{\text { Viscous Force }}=\frac{\omega^{2} \theta_{c}^{4} \rho^{2}}{\mu^{2}}$

The symbols stand for:

$$
\begin{aligned}
& \mathrm{g}=\text { gravitational acceleration, } \ell / \mathrm{t}^{2} \\
& \ell=\text { characteristic length or dimension, } \ell \\
& \mathrm{t}=\text { time }, \mathrm{t} \\
& \mathrm{T}=\text { temperature, } \mathrm{T} \\
& \beta=\text { temperature coefficient of volumetric expansion, } \mathrm{T}^{-1} \\
& \theta_{\mathrm{c}}=\text { clearance between cylinders, } \ell
\end{aligned}
$$




$$
\begin{aligned}
& \mu=\text { absolute viscosity, } \mathrm{m} / \ell \mathrm{t} \\
& \rho=\text { mass density, } \mathrm{m} / \ell^{3} \\
& \sigma_{\mathrm{t}}=\text { surface tension, } \mathrm{m} / \mathrm{t}^{2} \\
& \omega=\text { angular velocity, or rotational speed, } \mathrm{t}^{-1} \\
& \Delta \mathrm{t}=\text { temperature differential, } \mathrm{T} \\
& \mathrm{V}=\text { velocity or flow speed, } \ell / \mathrm{t} \\
& \mathrm{W}=\text { weight, } \mathrm{m} \ell / \mathrm{t}^{2} \\
& \mathrm{X}=\text { volume, } \ell^{3}
\end{aligned}
$$

Using the various values of graphite solid particles and copper alloy melt at the casting temperature, and with the necessary assumption of the effect of titanium on fractional reduction of surface tension, stirrer and the melt container, one can calculate the various dimensionless numbers for different particulate volume and melt temperature effects. Then these dimensionless numbers can be manipulated to obtain the necessary flow properties for effectively casting under different casting techniques, for example, permanent mold, pressure die, centrifugal and injection molding techniques of castings. This effort will be undertaken in the future work.

\subsection{Experimental Results and Discussion}

\subsubsection{Vortex and Bubble Formation Studies in Water}

Because molten copper has a viscosity of $3.6 \mathrm{cP}$ at the melting point and a lower value at the higher superheat temperature, water with $1 \mathrm{cP}$ viscosity can be used as model fluid.

Model experiments were conducted to determine the effectiveness of three kinds of stirrers designed and fabricated to improve the quality of suspension of graphite in copper alloys. The three kinds of stirrers having different blade angles, namely, 90 degrees, 60 degrees and 45 
degrees, have been used for this purpose. At each blade angle, the rpm of the stirrer was varied from 625 to $1500 \mathrm{rpm}$.

Figure 1 shows the vortex and bubble formation in water, when a 90 degree angle blade is used at different speeds. The photograph reveals that a vortex forms at an early stage of rotation at a speed of $625 \mathrm{mpm}$. It may be observed that water is mixed with heavy turbulence and large amounts of bubbles form at a speed of $750 \mathrm{rpm}$. The formation of bubbles during mixing has a detrimental effect on the casting. Since the density of the bubble is lesser than that of the melt, and their sizes larger than particles, the floatation velocity of the bubble is faster than that of the particle. With particles preferentially attached to the bubbles, the presence of bubbles enhances the floatation of particles.

In contrast to the above, a 60 degree blade angle stirrer gives interesting results. Figure 2 shows the behavior of water when a 60 degree angle blade stirrer is rotated at different speeds. The photographs clearly demonstrate that vortex will not form at the highest speed of $1250 \mathrm{rpm}$ under the present experimental conditions. In addition, it was observed that even at very high speeds, there was no significant bubble formation in water. A 45 degree angle blade stirrer indicated that up to a speed of $625 \mathrm{rpm}$ there was no vortex or bubble formation, as shown in .Fig. 3. At higher speeds of $1000 \mathrm{rpm}$ and above, there was significant vortex formation and bubble formation. The present experiments indicate that under the experimental conditions studied, a 60 degree angle blade stirrer performs more efficiently in distributing particles without formation of vortex and air bubbles. This type of 60 degrees stirrer was examined for Stage $I I$ in the synthesis of copper graphite composites while $90^{\circ}$ was used for Stage I. However, it should be kept in mind that in the actual synthesis of composites, the speed may not be the same as that obtained in model experiments since the viscosity of metals containing 
dispersed graphite particles will be higher than pure melt and may significantly influence the actual transport phenomena. Future laboratory experiments will be carried out in the presence of graphite particles and samples taken at different locations to determine the distribution of graphite in the liquid medium.

\subsubsection{Castings Studies}

\subsubsection{Graphite Distribution (Task 1)}

An extensive set of experiments were conducted to determine (1) graphite distribution and (2) the minimum desirable level of titanium to incorporate a known amount of graphite in the liquid metal. To begin with $0.5 \%, 1.0 \%$ and $1.5 \%$ of $\mathrm{Ti}$ was added to known amounts of yellow brass $(60 \mathrm{Cu}-40 \mathrm{Zn})$ and $\mathrm{C}-90300$ (Cu88-Sn8-Zn4) along with melts where no Ti was added. A known amount of graphite was added while the metal was being stirred. The addition of graphite was stopped as soon as graphite was observed on the surface of the melt without further getting into the liquid metal in spite of constant stirring. This visual technique was adopted to determine how much graphite can be introduced in a melt having a known amount of titanium.

Table 1 gives a summary of six samples made to optimize the quantity of wetting agent under one set of conditions. It may be noted that at a $0 \%$ titanium level, it was not possible to add any graphite under the present experimental conditions. It is quite evident from the data that the amount of titanium needed, using one stage stirring, appears to be one half of the amount of graphite to be added into the melt.

Chemical analyses of the composite castings were made to determine the amount of graphite along the length of 1 in diameter $8 \mathrm{in.}$ long castings for various amounts of graphite added in the melt. It is to be recognized, however, that these analyses determine the amount 
of carbon in the composite and all the carbon may not be in the form of graphite because some of the graphite may form $\mathrm{TiC}$ as thin layers on graphite particles. This type of analysis gives an idea of the actual recovery of graphite and the uniformity in the distribution of graphite along the length of the casting when the melt is stirred only once, without optimization of the relationship between the dimensions of the stirrer and the crucible. For the purpose of chemical analysis, drillings were taken every one inch interval from the top of the casting, along the longitudinal axis of the casting. Figures 4 and 5 show the typical distribution of carbon along the height of the castings in the form of bar chart for castings containing $1 \%$ and $2 \%$ graphite (targeted percentage). The conclusions drawn are based on several castings. Examination of the figures indicate that even though the targeted weight percentage of graphite in the alloys is varying from 1 to $2 \%$, all the castings exhibit a maximum of $0.27 \%$ of carbon. This indicates that under these experimental conditions with single stage stirring the recovery of graphite is very poor. It was observed that recovery of graphite was in the range of 10 to $15 \%$ of the targeted percentage. This result shows that in single stage stirring of graphite in the copper alloys, the recovery of graphite after solidification was less than satisfactory.

To improve these aspects, graphite was mixed in two stages using a 90 degree angle blade in stage one and a 60 degree angle blade in stage two. In the first stage, graphite was introduced by creating a high vortex in the liquid melt. This vortex was created to facilitate the easy introduction of graphite into the liquid metal and is necessary due to the four-fold density difference between graphite particles and the copper melt. During mixing, titanium was added to improve the wettability between the copper melt and graphite particles. In the second stage, the newly designed 60 degree angle blade stirrer was used to uniformly distribute the already introduced graphite inside the liquid, without creating a vortex and bubbles in the melt. The 
main function of the second stage is to stabilize graphite particles in the melt. Chemical analysis carried out on a 1 inch diameter bar poured under the above mentioned conditions is shown in the form of a bar graph in Fig. 6. This graph indicates the data on castings made under identical experimental conditions but under single-stage stirring, along with the results for two stage stirring. The figure clearly shows that the amount of graphite present in the castings, produced under two-stage stirring, is significantly higher than the castings produced under single-stage stirring. The stirring maximum percentage recovery of graphite was observed to be about $93 \%$, and the average recovery was observed to be about $80 \%$. It may be noted from the graph in Fig. 6 that the graphite content from bottom to top is quite uniform for all practical purposes, especially in the two stage stirring. A comparison of the overall recovery of graphite between single-stage stirring and two-stage stirring is illustrated in Fig. 7.

Repeatability of the two stage stirring technique is demonstrated in chemical analysis drillings taken from two castings as shown in Table 2. While the data are limited, several inferences can be drawn from Table 2 data as indicated in Table 3.

Several castings were made (DOE 22-26 and DOE 28) and drillings taken from them were analyzed in a similar manner. In all the castings about $1.5 \mathrm{wt} \%$ graphite and $1 \%$ Ti were added. The results are given below: 


\begin{tabular}{|c|c|c|c|}
\hline DOE Casting No. & $\begin{array}{c}\text { Average Graphite } \\
\text { Content, wt\% }\end{array}$ & $\begin{array}{c}\text { Graphite Added, } \\
\text { wt\% }\end{array}$ & $\begin{array}{c}\text { Recovery, } \\
\%\end{array}$ \\
\hline \hline 20 & 1.16 & 1.4 & 82 \\
21 & 1.03 & 1.4 & 74 \\
22 & 0.69 & 1.5 & 46 \\
23 & 0.75 & 1.5 & 50 \\
24 & 0.96 & 1.5 & 64 \\
25 & 1.22 & 1.5 & 81 \\
26 & 1.06 & 1.5 & 71 \\
28 & 1.18 & 1.5 & 80 \\
\hline
\end{tabular}

While in one case, the recovery is a low of $46 \%$, in general, the recovery is very significant, in the 70 to $80 \%$ range. In these castings with high recovery, for example, DOE 28,26 and 20, the distribution along the height is also very uniform as shown below:

\begin{tabular}{|r|c|c|c|}
\hline \multirow{2}{*}{ Position } & \multicolumn{3}{|c|}{ Graphite, wt\% } \\
\cline { 2 - 4 } & DOE \#28 & DOE \#26 & DOE \#20 \\
\hline \hline Top-1 & 1.204 & 0.985 & 1.261 \\
2 & 1.187 & 1.176 & 1.307 \\
3 & 1.178 & 1.043 & 1.255 \\
4 & 1.169 & 1.166 & 1.320 \\
5 & 1.162 & 0.995 & 1.183 \\
6 & 1.158 & 0.934 & 0.990 \\
Bottom 7 & 1.189 & 1.156 & 0.998 \\
Bottom 8 & $\ddots$ & & 0.981 \\
\hline
\end{tabular}

With new technologies for deagglomeration of as-received graphite powder which may contain as many as several hundred $5 \mu \mathrm{m}$ particles in 500 to $800 \mu \mathrm{m}$ clusters, and properly 
designed two-stage stirring techniques, it is expected that $80 \%$ graphite recovery and uniformity in graphite distribution along the ingot length could be achieved.

\subsubsection{Fluidity studies (Task 2)}

Suspension of solid particles in liquids is known to increase viscosity and decrease fluidity as well as influence the solidification processes and the microstructure of the matrix metal. In view of this, it is necessary to determine the fluidity and solidification characteristics of copper alloy-graphite composite melt for successful casting of these composites, because that will determine the size and the shape of castings which can be made.

Yellow brass (Cu:60\%, $\mathrm{Zn}: 40 \%)$ has been used for fluidity tests. The process used for synthesis of the copper-graphite composite involved a two-stage stirring process. The fluidity of the copper-graphite composite was measured by casting fluidity spirals in permanent steel molds. The steel mold was preheated to $260 \mathrm{C}$ with heating cartridges embedded in the mold. A refractory pouring cup coated with boron nitride was used to maintain velocity and laminar flow of the composite slurry in the mold.

The chemical compositions of different yellow brass-graphite alloys studied and their pouring temperatures are given in Table 4. A typical copper-graphite composite fluidity spiral is shown in Fig. 8. The lengths of fluidity spirals of the base alloy and its composites containing various amounts of graphite are plotted in the form of bar graph in Fig. 9. The spiral length of the base yellow brass alloy (no Ti) increases by about $60 \%$ with an increase in temperature from 950 to $975 \mathrm{C}$. At $960 \mathrm{C}$, with $1.5 \% \mathrm{Ti}$, the fluidity decreases with an increase in graphite content, as expected. However, the fluidity of yellow brass containing $1.5 \%$ Ti and up to $1.5 \%$ graphite remains adequate for making a variety of castings, as indicated from the length of the spirals. At the most, a slightly higher pouring temperature may be required 
for casting graphite containing yellow brass as compared to conventional yellow brass of the same matrix composition.

\subsubsection{Directional Solidification (Task 3)}

Directional solidification experiments were conducted to determine the effect of cooling rate on the uniformity of graphite particle distribution and microstructure. As mentioned earlier, a uniform graphite distribution depends on the deagglomeration of graphite particles added to the melt as well as on the as-received graphite condition. In addition, the distribution of graphite particles is affected by the cooling rate due to the interaction between the growing dendrite arm and graphite particles. When the growing dendrite arms interact with graphite particles, they usually push the graphite particles into the interdendritic regions. Also, the distribution of graphite particles depends on the cooling rate which influences the dendrite arm spacing.

Copper C90300 alloy with $1.5 \mathrm{wt} \% \mathrm{Gr}$ and $2 \mathrm{wt} \% \mathrm{Ti}$ (DOE 20) was used in this experiment. The experimental setup used is shown in Fig. 10. The change in the temperature of copper melt with time was measured by the thermocouples placed in the mold. The thermocouples were connected to a recorder to record the temperature change of the molten metal with time. The ceramic mold coated with a boron nitride wash was preheated to $1500 \mathrm{C}$ in an electrical resistance furnace. A copper chill was precooled in a freezer at a temperature of $-12 \mathrm{C}$ before setting below the mold.

A typical cooling curve obtained from the bottom and the upper parts of the sample is shown in Fig. 11. It may be noted that in the initial period, the temperature drop rate at the bottom part (curve a) is greater than that at the upper part due to the high cooling rate produced by the chill which controls the directional solidification condition. The cooling curves show that 
at the bottom part (curve a), no plateau appears; the local solidification rate at the bottom part is so fast that the recorder used in this experiment was not able to respond to it. However, the plateau appears at the upper part (curve a) due to the lower cooling rate as well as the longer local solidification time which can be measured. The cooling rates for both parts of the casting appear to stabilize after about 120 seconds. The cooling rate at the bottom part is around $20 \mathrm{C} / \mathrm{s}$, and $4 \mathrm{C} / \mathrm{s}$ at the middle part, as shown in Fig. 12.

It was observed in the microstructure that a very fine structure was obtained near the chill surface and progressively coarser structures in the middle and the upper parts, as shown in Fig. 13. Figure 13 shows that the graphite particles are present mainly in the upper part of the directionally solidified casting. This was probably due to the high floatation velocity of graphite particles resulting from the preexisting agglomeration of graphite particles. Generally, the distribution of graphite particles is expected to improve under the high cooling rates in thinner sections castings due to the reduction of floatation time of graphite particles. However, these observations show that a cooling rate of $20 \mathrm{C} / \mathrm{s}$ may not be fast enough to significantly help in improving the distribution of graphite particles under present experimental conditions (where preexisting agglomerated particles do not deagglomerate in melt due to stirring). Thus to improve graphite distribution, the graphite particles must be greatly deagglomerated before their addition as well as during mixing, and the cooling rate should be enhanced. In addition to macrosegregation to the top part of the casting, the graphite particles are found to be present in the interdendrite region resulting from graphite particles being pushed by the growing dendrite (Fig. 13c). This is one of the problems to be solved to improve the distribution of graphite particles in the solidified matrix. 


\subsubsection{Microstructure Analysis of Fluidity Spirals}

Metallographic samples from different locations of a fluidity spiral (Fig. 8) were examined under optical microscope to observe the presence of graphite particles and the microstructure of the metal matrix. The dendrite arm spacing of samples taken from different locations of the castings fluidity spiral was also measured using the optical microstructure.

An important feature of the copper alloy-graphite composite casting is the nature of graphite particle distribution throughout the casting. The results of the measurements of particle distribution showed that the volume fraction of particles in fluidity spiral varied with locations within the spiral.

Typical microstructures from two positions of fluidity spirals of copper alloy-graphite composite are shown in Fig. 14. It is apparent from this figure as well as Figure 15 and 16 that graphite particles originally of $5 \mu \mathrm{m}$ size are present in large agglomerated clusters in the copper alloy castings; in addition there is variation in the amount of graphite present in different parts of the spiral. The floatation velocity of these several $100 \mu \mathrm{m}$ size cluster of graphite particles will be much higher than that of 5-10 $\mu \mathrm{m}$ individual particles according to Stoke's law. This agglomeration apparently contributes to the macrosegregation of graphite in cylindrical and spiral .casting. Thus, it is very necessary to deagglomerate graphite clusters before addition into the melt, and retain them as individual deagglomerated particles in the casting.

Figure 16 showing the microstructure of the composite at two positions (\#1 and \#6) of the same fluidity spiral, indicates that(a) there was significant agglomeration of graphite and (b) there is a second phase around graphite particles which is most likely $\mathrm{TiC}$ particles. The thickness of the reaction layer may influence the machinability of copper alloy-graphite composite, the control of thickness of this reaction layer is important. 
Micrographs indicate no significant difference in average secondary dendrite arm spacing of the matrix metal at the different locations on the same spiral Figure 14-16. The results of measurements of the dendrite arm spacing for yellow brass-1.5 wt \% graphite composite are shown in Fig. 17. The very similar secondary arm spacings at different locations of the spiral suggest that the cooling rates and retain them as individual deagglomerated particles in the casting.

\subsubsection{Floatation}

The floatation of graphite particles in copper matrix composite melt was studied on yellow brass-based matrix alloy with $0.8 \mathrm{wt} \%$ of graphite. This material was produced in an induction furnace. An intensive mixing of graphite powder was performed for deagglomeration of graphite particles before their introduction into molten alloy.

The macrostructures of two types of castings obtained after 0 and 10 minutes of holding time during floatation experiments are shown on Figs. 18, 19, respectively:

Macroexamination of the longitudinal section of the zero holding time castings (Figure 18) suggests no significant graphite floatation in the casting; microscopic examination showed graphite distribution over the entire height of the casting and the presence of graphite apparently refines the grain size. Macroscopically this sample appears to be free of defects such as structural discontinuities. On the contrary, macroexamination of the second casting poured after ten minutes holding shows the formation of two markedly different regions. The graphite-rich and graphite-free region apparently formed due to floatation of graphite particles; these two regions (graphite free and graphite rich) are separated by an easily identifiable boundary because the grain size is finer in the graphite rich region. From the macro sections, the extent of the graphite rich zone and the height of the floatation, i.e., the location of the clearly marked 
boundary from the castings bottom, were measured. A plot of the relative floatation height $(\mathrm{h} / \mathrm{H})$, where $\mathrm{h}$ is the floatation height and $\mathrm{H}$ is the total casting height versus isothermal holding time, is shown in Fig. 20. It is noted that the floatation height increases very rapidly at the initial stages but there was no additional floatation beyond the 10 minutes holding.

Grain structures of the two regions of the casting made after holding (Figure 19) are distinctively different. The as-cast grains in the graphite-rich zone appear much finer than in the graphite-free zone: the average size of grains in these zones are $2 \mathrm{~mm}$ and $8 \mathrm{~mm}$ for 10 minutes holding time, and $1.4 \mathrm{~mm}$ and $10 \mathrm{~mm}$ for 20 minutes of isothermal holding. In comparison, the average size of grains in castings made without isothermal holding (Figure 19) appears to be approximately $2.5 \mathrm{~mm}$. But it must be noted that there is some difference in the grain size of this casting section from bottom to top even though one does not macroscopically observe the formation of two clearly separated regions. The grain size decreases gradually from approximately $3 \mathrm{~mm}$ near the bottom part of casting to $0.5 \mathrm{~mm}$ in the layer at the upper part; suggesting some floatation of graphite. The results are indicative of the fact that the graphite particles play a role in modifying structure and result in a refinement of cast grain size in this copper alloy

\section{CONCLUSIONS}

The significant conclusions from the first year's study are summarized below:

1. Stirring of uncoated graphite alone in the $\mathrm{Cu}$ melt did result in incorporation of any significant amounts of graphite in the melt or in the castings. 
2. It is possible to disperse 1.0 to $2.0 \mathrm{wt} \%$ graphite in $\mathrm{Cu}$ alloy melts and castings by adding 0.5 to $1.0 \mathrm{wt} \% \mathrm{Ti}$ to the melts. Over twenty heats of graphite containing copper were successfully made during this year.

3. Percentage of recovery of graphite in the copper-gaphite castings was observed to be higher with a higher wt \% of Ti added to the copper melt.

4. An average of $80 \%$ incorporation of the added graphite could be achieved by a two-stage stirring technique and with the higher amount of $\mathrm{Ti}$ addition. The recoveries of graphite using the two stage stirring technique are much higher than those obtained in single stage stirring.

5. Significant graphite clustering is observed in the microstructure of the castings made to date. Additional efforts will continue to deagglomerate graphite clusters before addition, and efforts will be made to retain uniformly distributed individual particles in the final casting.

6. Secondary dendrite arm spacing was not significantly affected due to graphite additions of up to $1.5 \mathrm{wt} \%$ indicating that the cooling rate of copper alloys was not significantly influenced by graphite additions.

7. A graphite-free zone formed in some castings as a result of the floatation of graphite particles with increasing time of isothermal holding.

8. The presence of the graphite particles results in a refinement of grain size in copper alloys, and an improvement in their machinability. 


\section{RECOMMENDATIONS AND FUTURE WORK}

A significant uniform distribution of graphite particles was realized through the design of a new stirrer and adaption of a two-stage stirring technique. However, before the addition of graphite particles in the copper melt, clusters of graphite particles must be broken down. In the case of fine graphite particles $(5-10 \mu \mathrm{m})$, clustering before addition significantly influences the distribution of graphite particles in the melt. Even though graphite particles are heated up in the oven to reduce their moisture content, the short range forces acting between fine particles do not disappear under intensive stirring. Therefore, to deagglomerate as-received graphite particles, other techniques involving ball milling with brass, or copper powders, are under development.

The presence of graphite particles increases the viscosity of the copper melt. Also, in the present laboratory setup, during mixing, the power (melt heating) must be shut off thereby increasing the viscosity of the copper melt. In addition, some floatation of graphite particles at or near the melt surface results in difficulties in top pouring the melt into the mold. To solve this problem, a bottom pouring technique is recommended to reduce the difficulties in pouring the melt. A graphite stirrer is recommended to stir the copper melts. These modifications will help in keeping the melt temperature at the desired level.

Machinability depends on the uniform distribution of graphite particles with minimal TiC formation. Thus a quantification of the reaction layer of TiC is necessary as a function of time and temperature. During mixing, the turbulence in the melt and its temperature influence the thickness of the TiC layer on each graphite particle. Therefore, to obtain an adequate machinability of the copper alloy-graphite composite, the reaction layer thickness must be quantified in terms of temperature and the $\mathrm{pm}$ of the stirrer. 
Future work will also be directed to improve the distribution of graphite in static castings, and to develop techniques for centrifugal casting where graphite particles can be concentrated near the inner periphery of bearings where they are required for lubrication purposes.

Table 1. Experiments to Optimize Wetting Agent Addition

\begin{tabular}{|c|c|c|c|c|}
\hline $\begin{array}{l}\text { Sample } \\
\text { No. }\end{array}$ & Alloy & $\begin{array}{c}\text { Wetting } \\
\text { Agent, Ti } \\
\text { wt\% }\end{array}$ & $\begin{array}{l}\text { Graphite, } \\
\text { wt\% }\end{array}$ & Remarks \\
\hline $\begin{array}{c}1 \\
(\mathrm{DOE} 3)\end{array}$ & $\begin{array}{l}\text { Yellow } \\
\text { Brass }\end{array}$ & 0 & 1.0 & $\begin{array}{l}\text { Visual observation indicated that there } \\
\text { was no graphite getting into the melt } \\
\text { after stirring for } 30 \text { secs. }\end{array}$ \\
\hline $\begin{array}{c}2 \\
\text { (DOE 4) }\end{array}$ & $\begin{array}{l}\text { Yellow } \\
\text { Brass }\end{array}$ & 0.25 & 0.42 & $\begin{array}{l}\text { Addition of graphite powder was } \\
\text { stopped the moment graphite was } \\
\text { observed on the surface. }\end{array}$ \\
\hline$\stackrel{3}{3}$ (DOE 7$)$ & $\begin{array}{l}\text { Yellow } \\
\text { Brass }\end{array}$ & 0.5 & 1 & $\begin{array}{l}\text { It was observed that } 0.5 \% \text { of } \mathrm{Ti} \text { was } \\
\text { just enough to add } 1 \text { wt } \% \text { of graphite. }\end{array}$ \\
\hline $\begin{array}{c}4 \\
\text { (DOE } 8)\end{array}$ & $\begin{array}{l}\text { Yellow } \\
\text { Brass }\end{array}$ & 0.5 & 1 & $\begin{array}{l}\text { It is a repetition of DOE } 7 \text { to check } \\
\text { repeatability. }\end{array}$ \\
\hline $\begin{array}{c}5 \\
(\mathrm{DOE} 9)\end{array}$ & $\begin{array}{l}\text { Yellow } \\
\text { Brass }\end{array}$ & 1 & 2 & $\begin{array}{l}\text { It was possible to add } 2 \% \text { graphite } \\
\text { with } 1 \% \mathrm{Ti} \text {. However, the composite } \\
\text { melt was very viscous. }\end{array}$ \\
\hline $\begin{array}{c}6 \\
(\mathrm{DOE} 10)\end{array}$ & $\begin{array}{l}\text { Yellow } \\
\text { Brass }\end{array}$ & 1 & 2 & Repetition of DOE 9. \\
\hline
\end{tabular}


Table 2. An Analysis of Two Castings for Repeatability

\begin{tabular}{|r|c|c|c|c|c||}
\hline \multicolumn{3}{|c|}{ Cast No. DOE 20 } & \multicolumn{3}{c|}{ Cast No. DOE 21 } \\
\hline $\begin{array}{c}\text { Drilling } \\
\text { Position }\end{array}$ & $\begin{array}{c}\text { Analyzed } \\
\text { Carbon } \\
\text { Content \% }\end{array}$ & $\begin{array}{c}\text { Carbon }^{2} \\
\text { Recovery \% }\end{array}$ & $\begin{array}{c}\text { Drilling } \\
\text { Position }\end{array}$ & $\begin{array}{c}\text { Analyzed } \\
\text { Carbon } \\
\text { Content \% }\end{array}$ & $\begin{array}{c}\text { Carbon }^{2} \\
\text { Recovery } \\
\%\end{array}$ \\
\hline \hline Top 1 & 1.261 & 90.1 & Top 1 & 1.071 & 76.5 \\
\hline 2 & 1.307 & 93.3 & 2 & 1.024 & 73.1 \\
\hline 3 & 1.255 & 89.6 & 3 & 1.094 & 78.1 \\
\hline 4 & 1.320 & 94.3 & 4 & 1.069 & 76.4 \\
\hline 5 & 1.183 & 84.5 & 5 & 1.068 & 76.3 \\
\hline 6 & 0.990 & 70.7 & 6 & 0.849 & 60.6 \\
\hline 7 & 0.998 & 71.3 & 7 & 1.048 & 74.9 \\
\hline Bottom 8 & 0.981 & 70.1 & Bottom 8 & 1.048 & 74.9 \\
\hline Average & 1.162 & 83.0 & Average & 1.033 & 73.9 \\
\hline
\end{tabular}

${ }^{a}$ Graphite added $1.4 \mathrm{wt} \%$. Additional losses may amount to 2 to $5 \%$ of the quantity added. Titanium added is $2 \mathrm{wt} \%$. Base alloy C 90300 . 
Table 3. Some Observations on Table 2 Data

\begin{tabular}{|c|c|c|}
\hline Items & DOE \#20 & DOE \#21 \\
\hline $\begin{array}{l}\text { 1. Range of maximum variation in graphite } \\
\text { content, wt } \%\end{array}$ & $\begin{array}{c}0.981 \text { to } 1.320 \text { or } \\
0.339\end{array}$ & $\begin{array}{l}0.849 \text { to } 1.094 \\
\quad \text { or } 0.245\end{array}$ \\
\hline $\begin{array}{l}\text { 2. Maximum variation as a fraction of } \\
\text { graphite added, } \%\end{array}$ & 24 & 18 \\
\hline $\begin{array}{l}\text { 3. Maximum variation between the top and } \\
\text { bottom graphite levels, wt } \%\end{array}$ & $\begin{array}{lr}\text { Top } & 1.261 \\
\text { Bottom } & 0.981 \\
\text { Difference } & 0.28\end{array}$ & $\begin{array}{lr}\text { Top } & 1.07 \\
\text { Bottom } & 1.048 \\
\text { Difference } & 0.022\end{array}$ \\
\hline 4. Location of minimum graphite level & Bottom & $\begin{array}{l}\text { Three inches } \\
\text { from the bottom }\end{array}$ \\
\hline $\begin{array}{l}\text { 5. Graphite recovery fraction in the top half } \\
\text { of the rod, } \%\end{array}$ & 91.8 & 76.0 \\
\hline $\begin{array}{l}\text { 6. Overall graphite recovery in DOE } \# 20 \\
\text { and DOE } \# 21 \text { castings. }\end{array}$ & 83.0 & 73.9 \\
\hline
\end{tabular}


Table 4. Yellow Brass-Graphite Composite Fluidity-Spiral Evaluation

\begin{tabular}{|c|c|c|c|c|}
\hline \hline $\begin{array}{c}\text { DOS } \\
\text { Sample \# }\end{array}$ & $\begin{array}{c}\text { Ti Content, } \\
\text { wt\% }\end{array}$ & $\begin{array}{c}\text { Graphite } \\
\text { Content, wt\% }\end{array}$ & $\begin{array}{c}\text { Pouring } \\
\text { Temp., }{ }^{\circ} \mathbf{C}\end{array}$ & $\begin{array}{c}\text { Spiral Length, } \\
\mathbf{~ c m}\end{array}$ \\
\hline \hline 30 & 0 & 0 & 950 & 15.6 \\
\hline 32 & 0 & 0 & 975 & 24.0 \\
\hline 34 & 1.5 & 0 & 960 & 19.1 \\
\hline 35 & 1.5 & 1 & 960 & 13.6 \\
\hline 37 & 1.5 & 1.5 & 960 & 12.8 \\
\hline
\end{tabular}




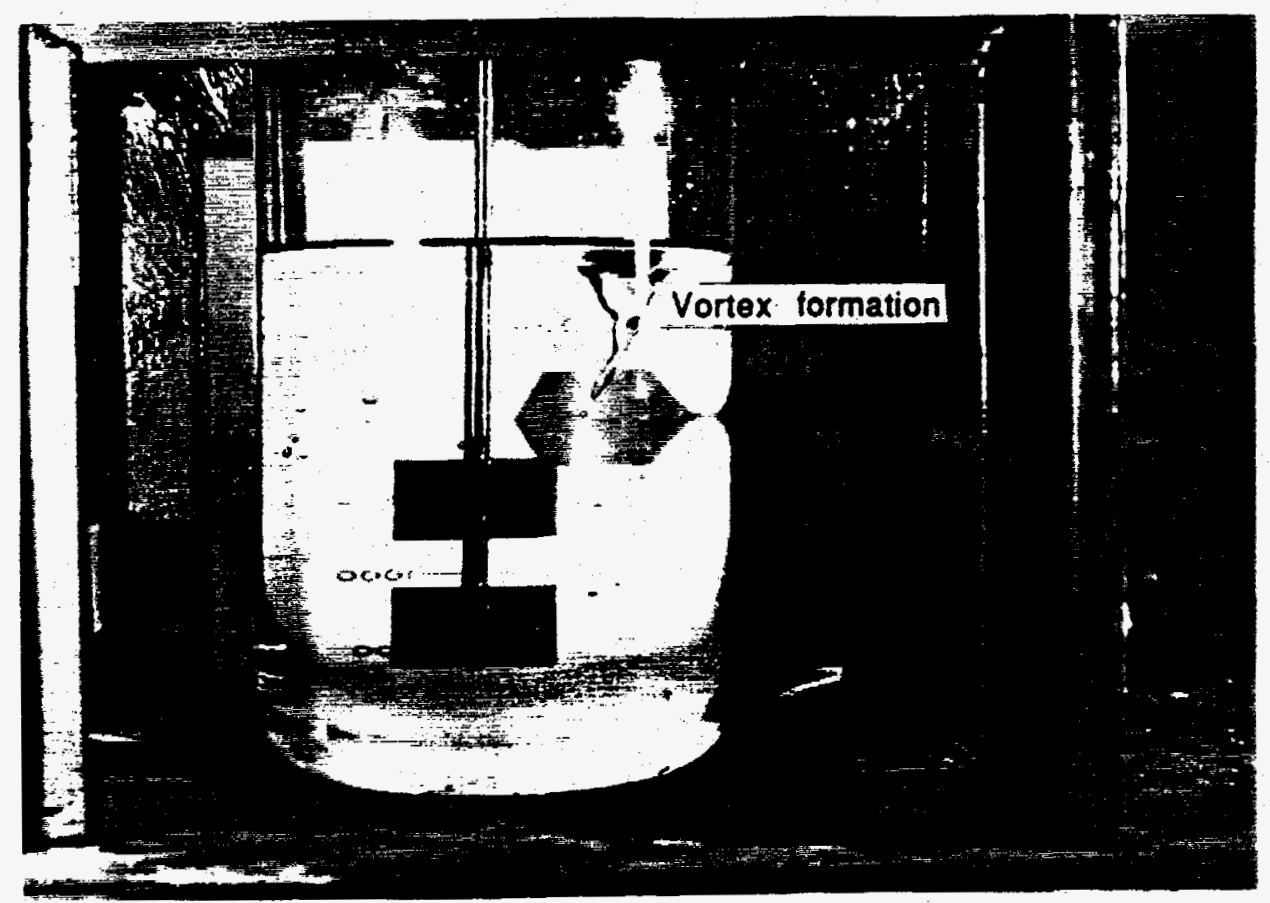

(a) $625 \mathrm{rpm}$

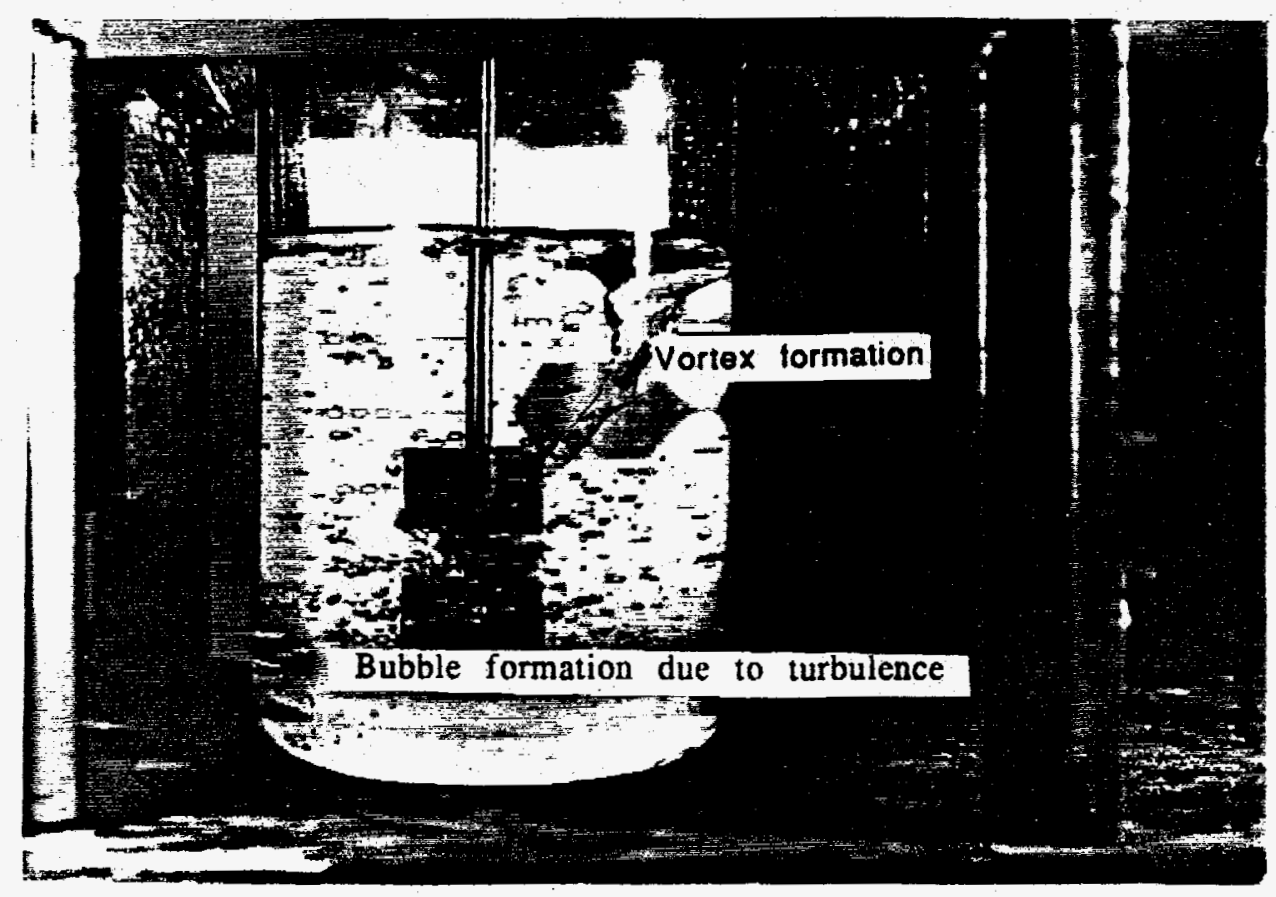

(b) $750 \mathrm{rpm}$

Fig. 1. Bubble and vortex formation when 90 degree blades are used to stir water at different speeds. 


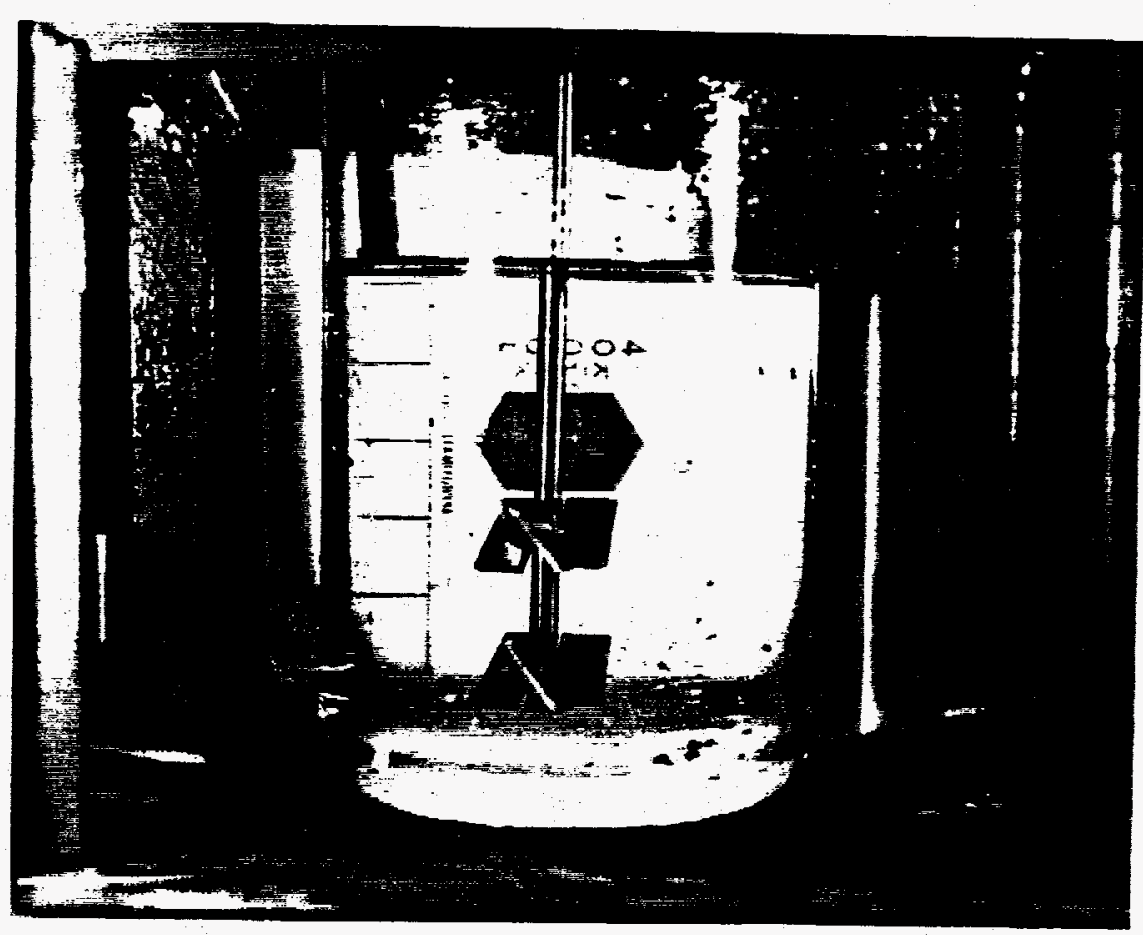

(a) $1000 \mathrm{rpm}$

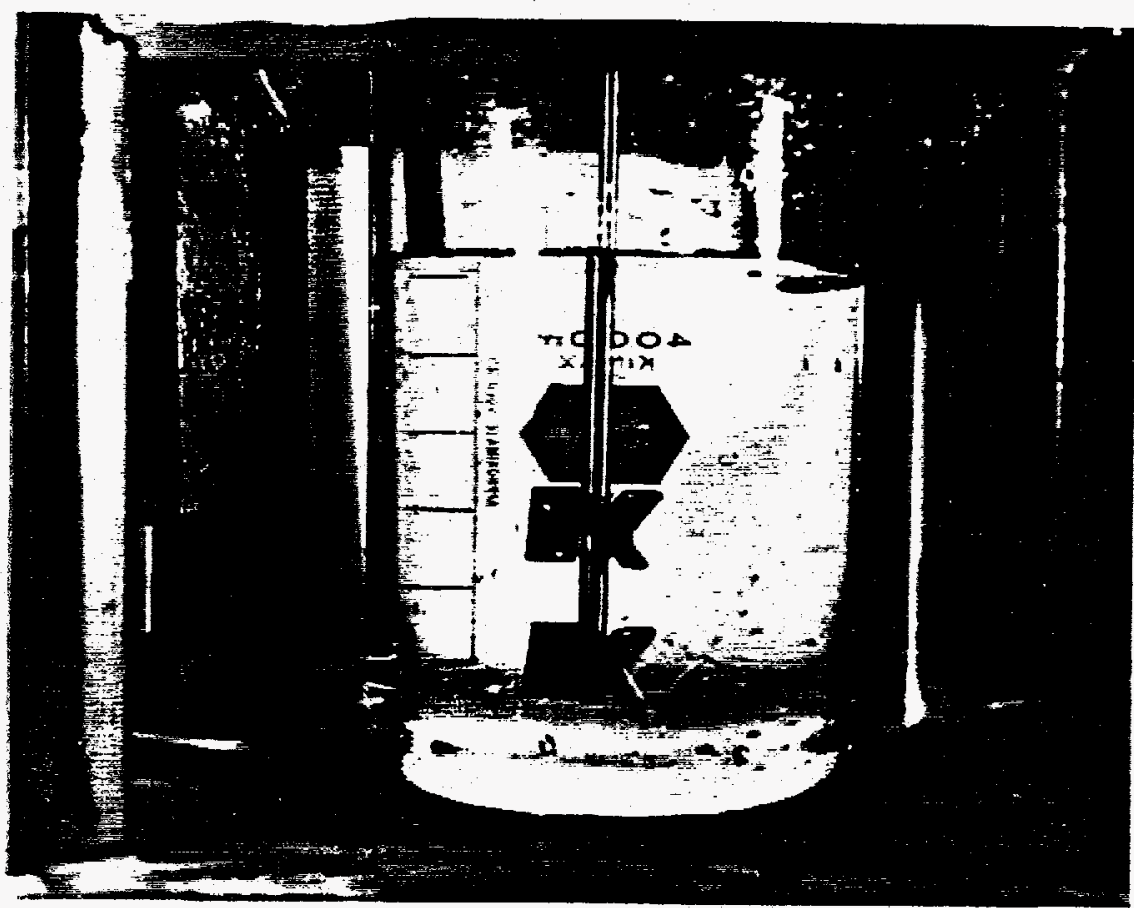

(b) $1250 \mathrm{rpm}$

Fig. 2. Bubble and vortex formation when 60 degree blades are used to stir water at different speeds. 


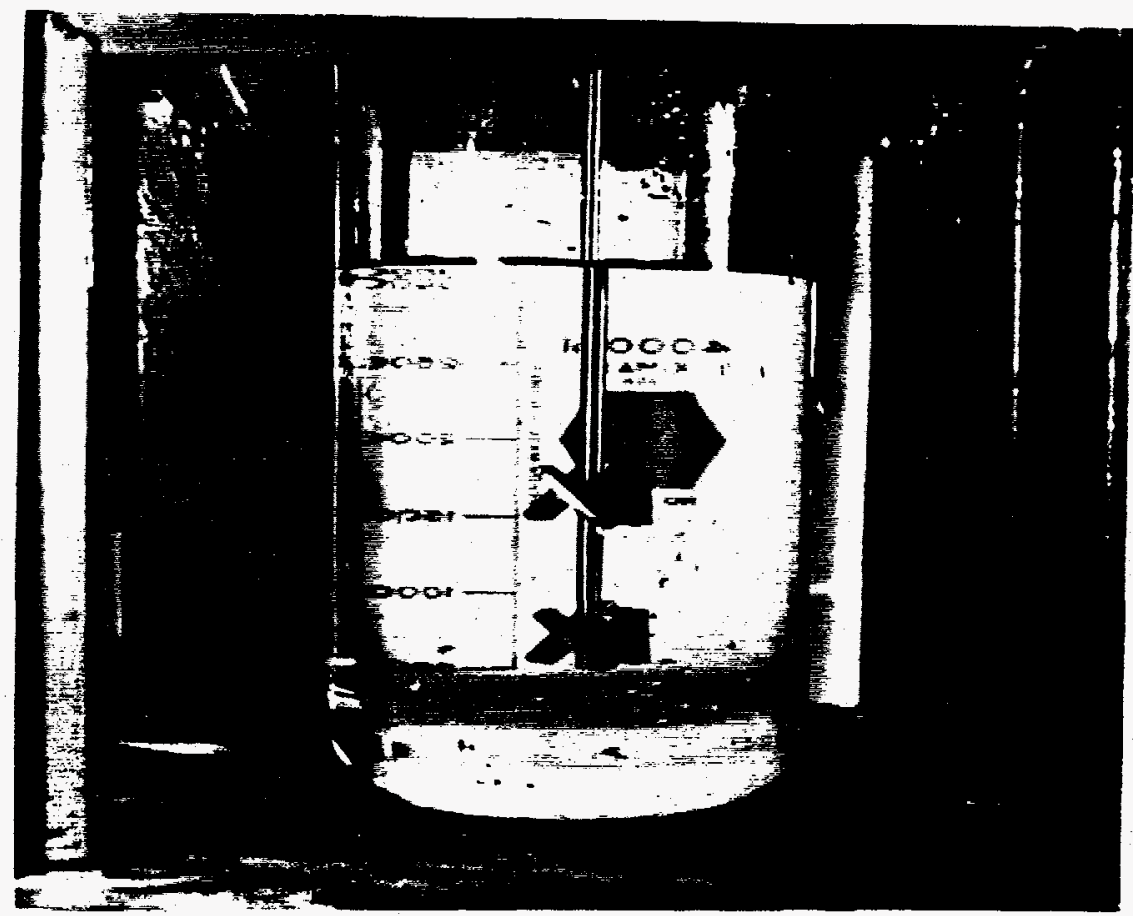

(a) $625 \mathrm{rpm}$

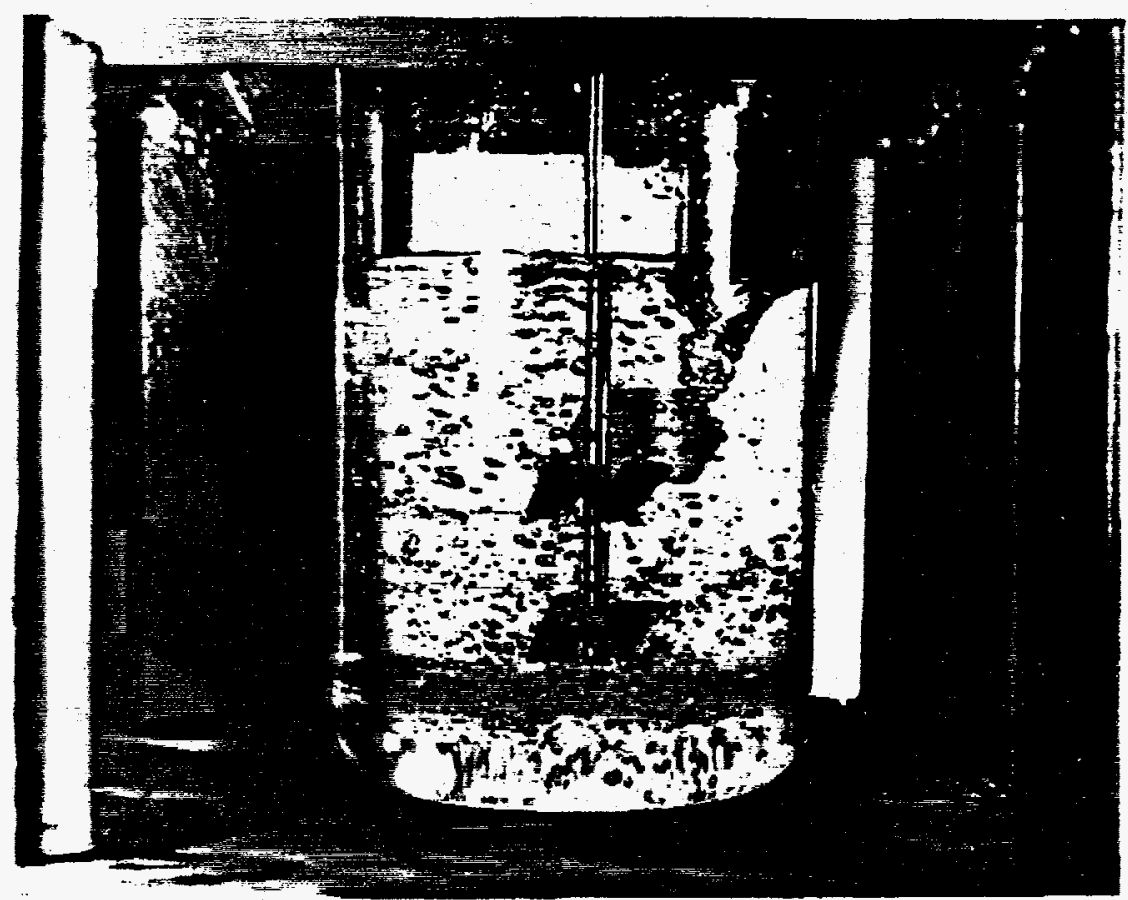

(b) $1000 \mathrm{rpm}$

Fig. 3. Bubble and vortex formation when 45 degree blades are used to stir water at different speeds. 


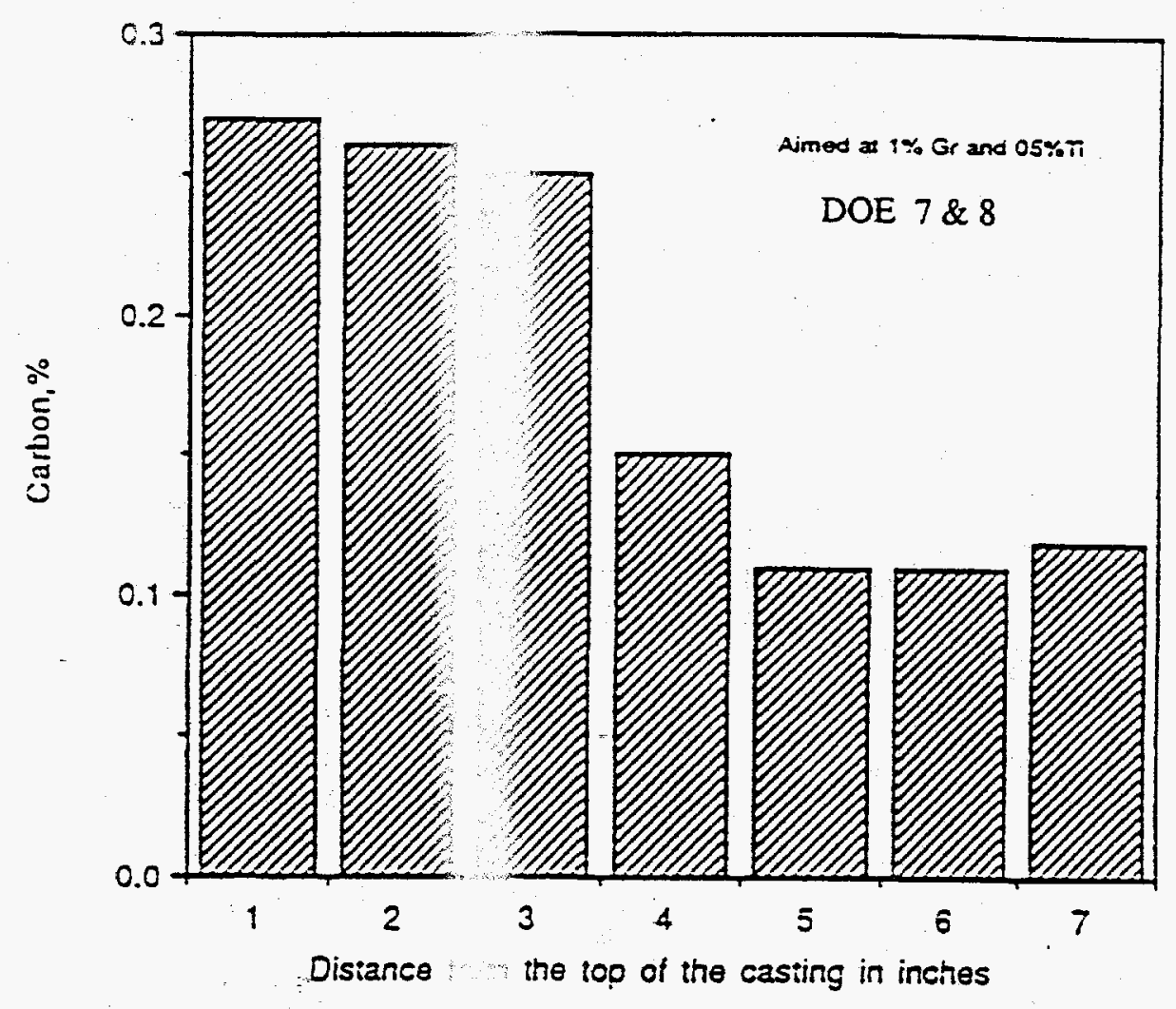

Fig 4. Chemical analysis of carbon along the length of 1 inch diameter rod (DOE 7 and 8). 


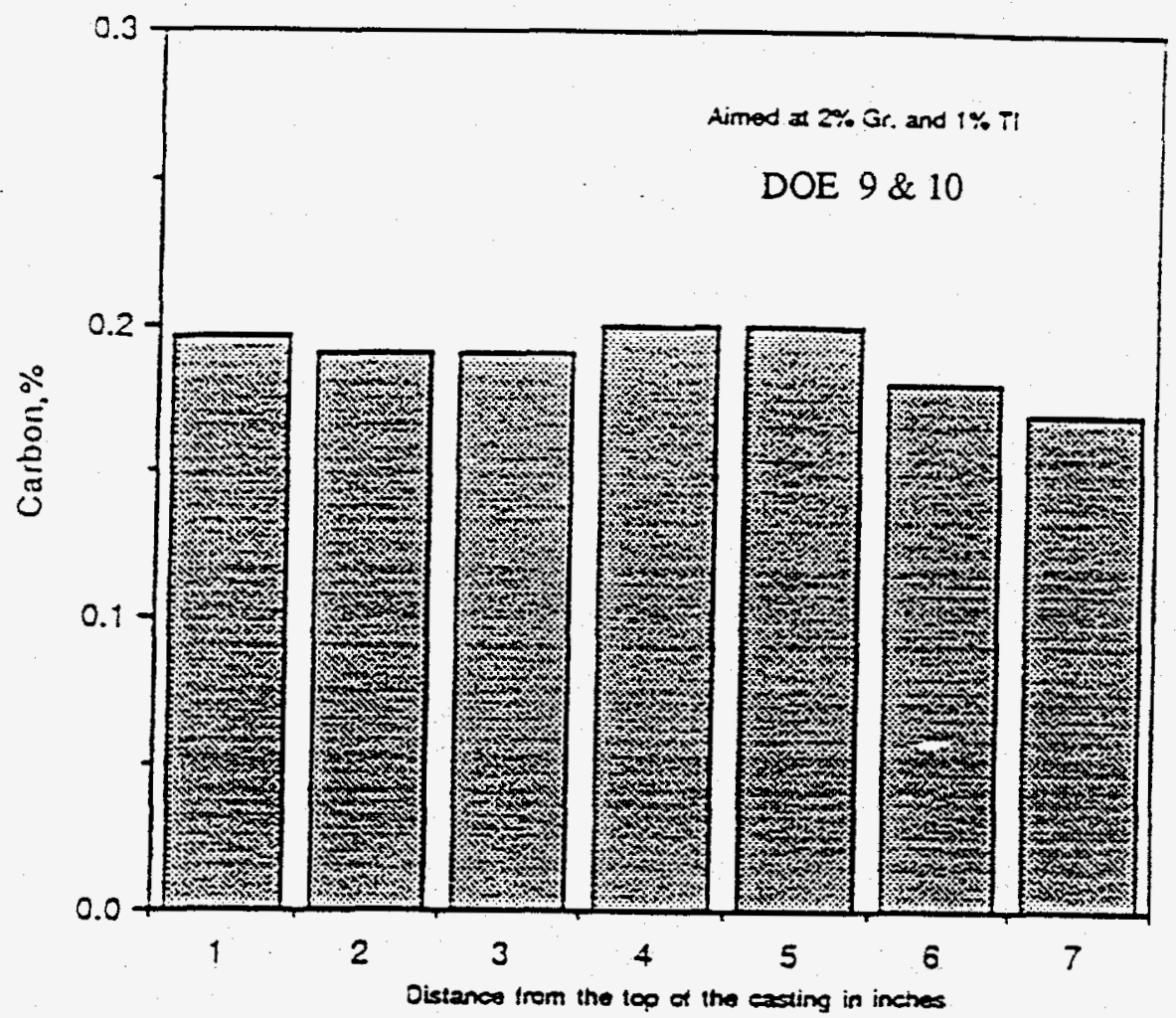

Fig 5. Chemical analysis of carbon along the length of 1 inch diameter 


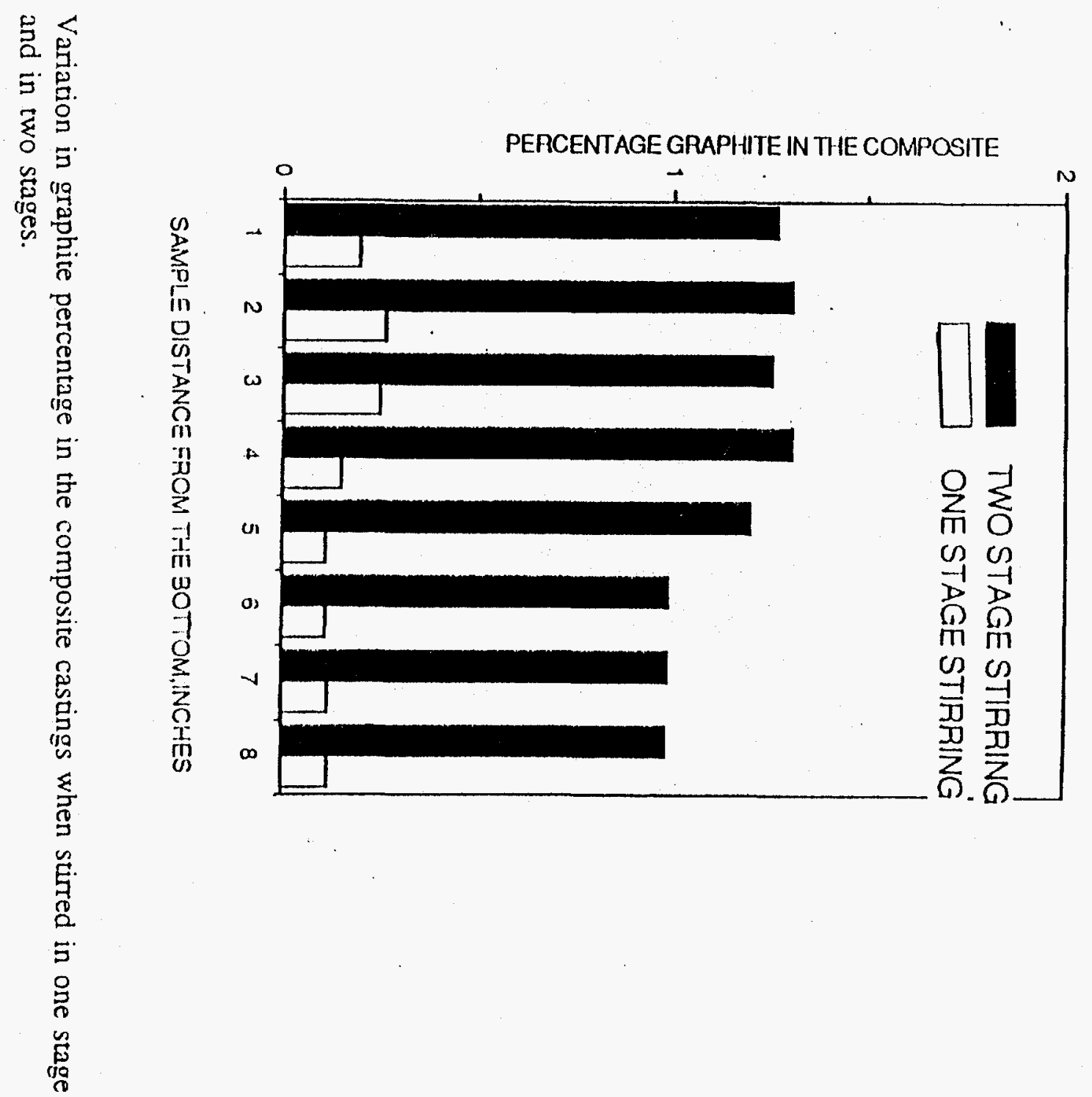




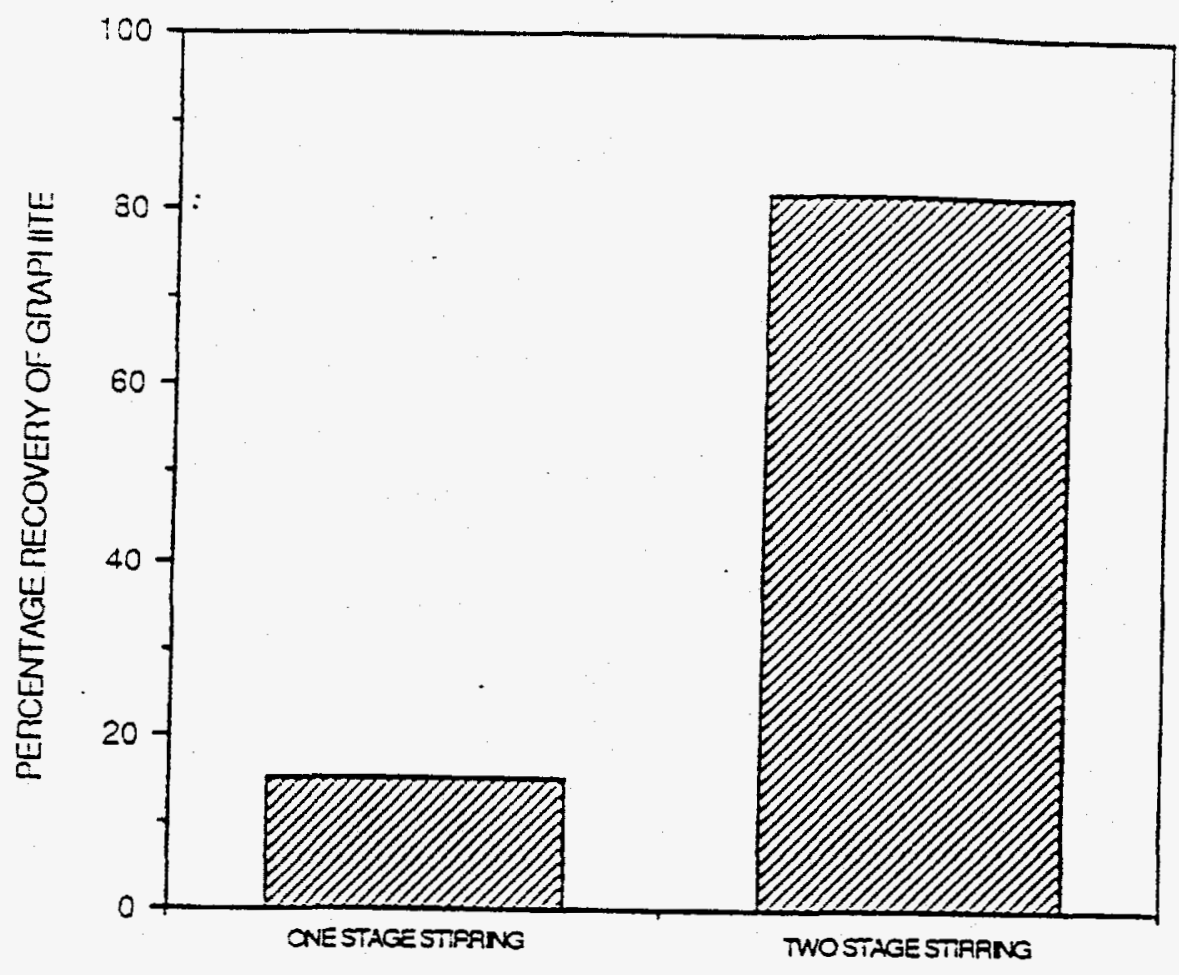

Fig. 7. Improvement in graphite recovery due to two stage strring: this may permit lower amounts of titanium required. 


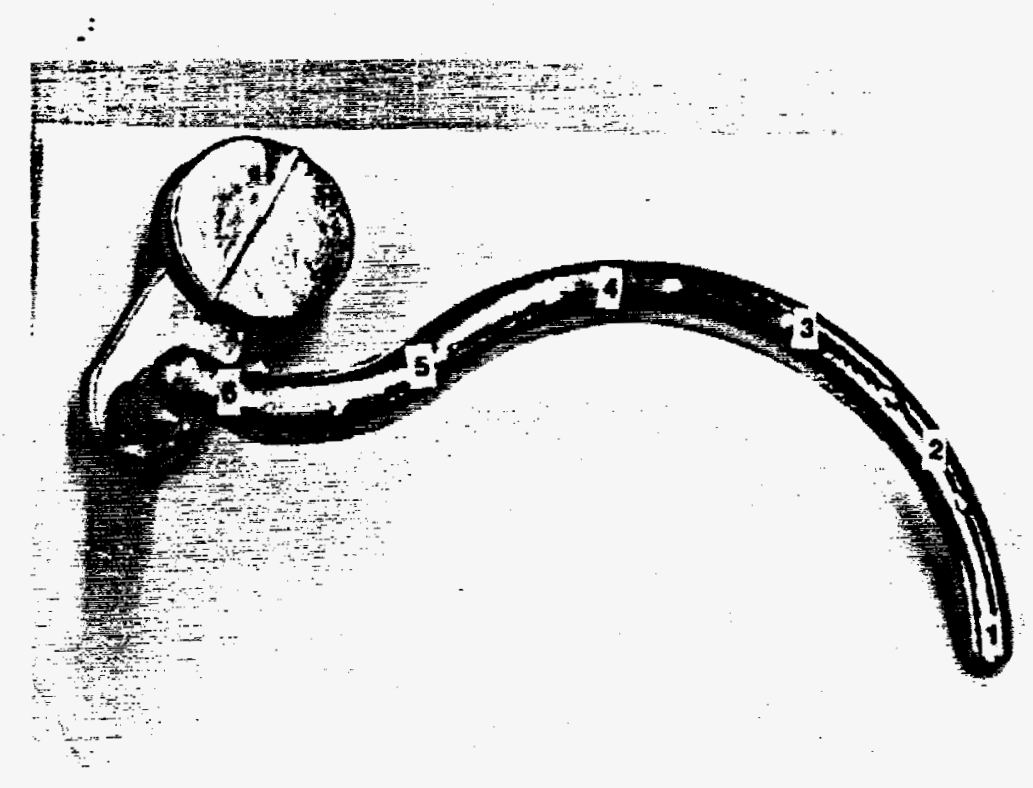

Fig. 8. Locations from which samples were taken for metallographic examination. 


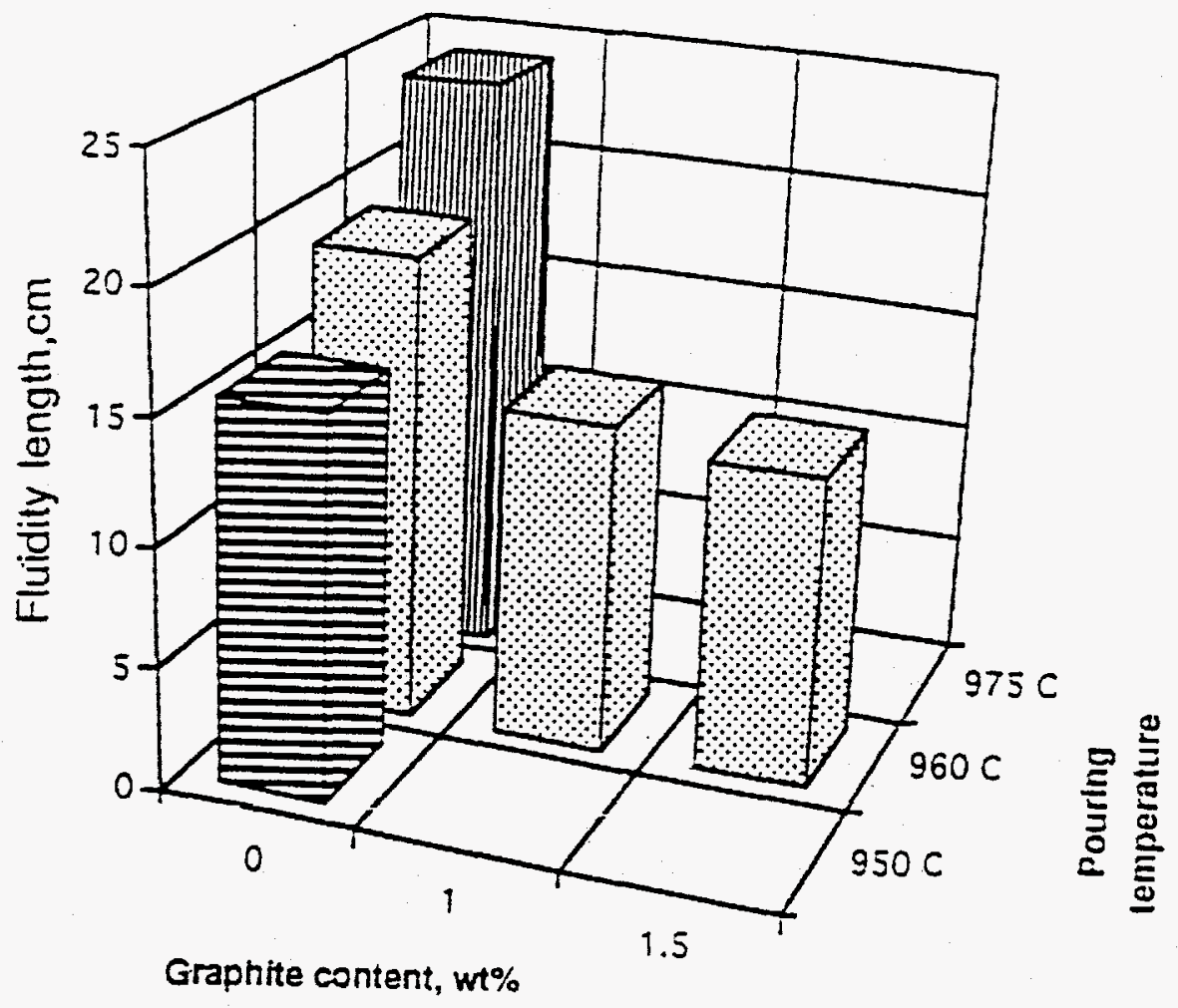

Fig 9. The fluidity of yellow brass and copper-graphite composites slurry, variation of fluidity with different graphite contents. The C90300 castings contained $1.5 w t \% \mathrm{Ti}$, others had no Ti. 


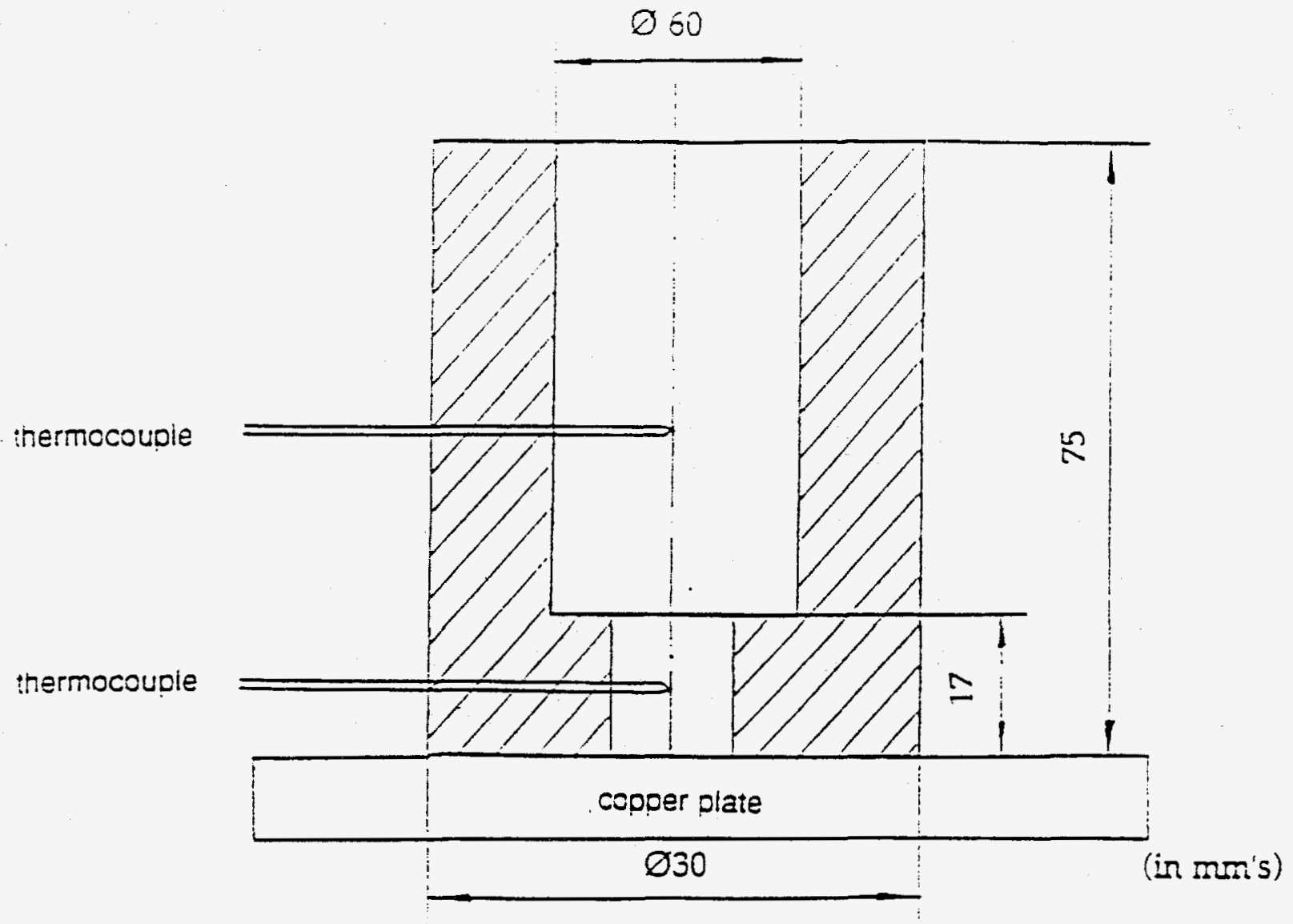

Fig. 10. Schematic illustration of the directional solidification experimental setup. 


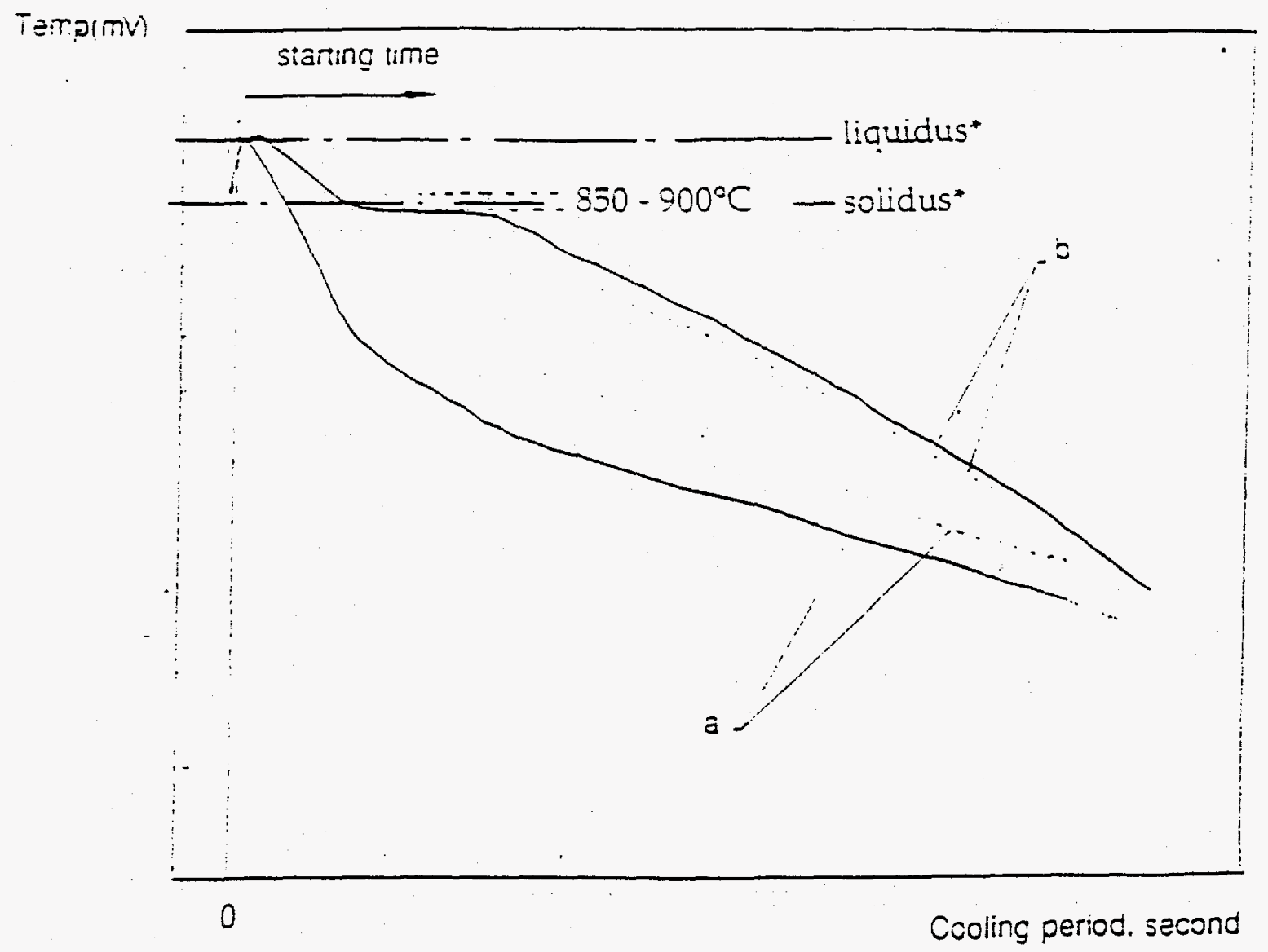

* for C90300 ailoy

Fig. 11. Typical cooling curves of $C 90300$ of copper alloy-graphite composite in directional solidification experiments. The thermocouples are located neat the bottom (a), and central and upper (b) parts of the mold. 


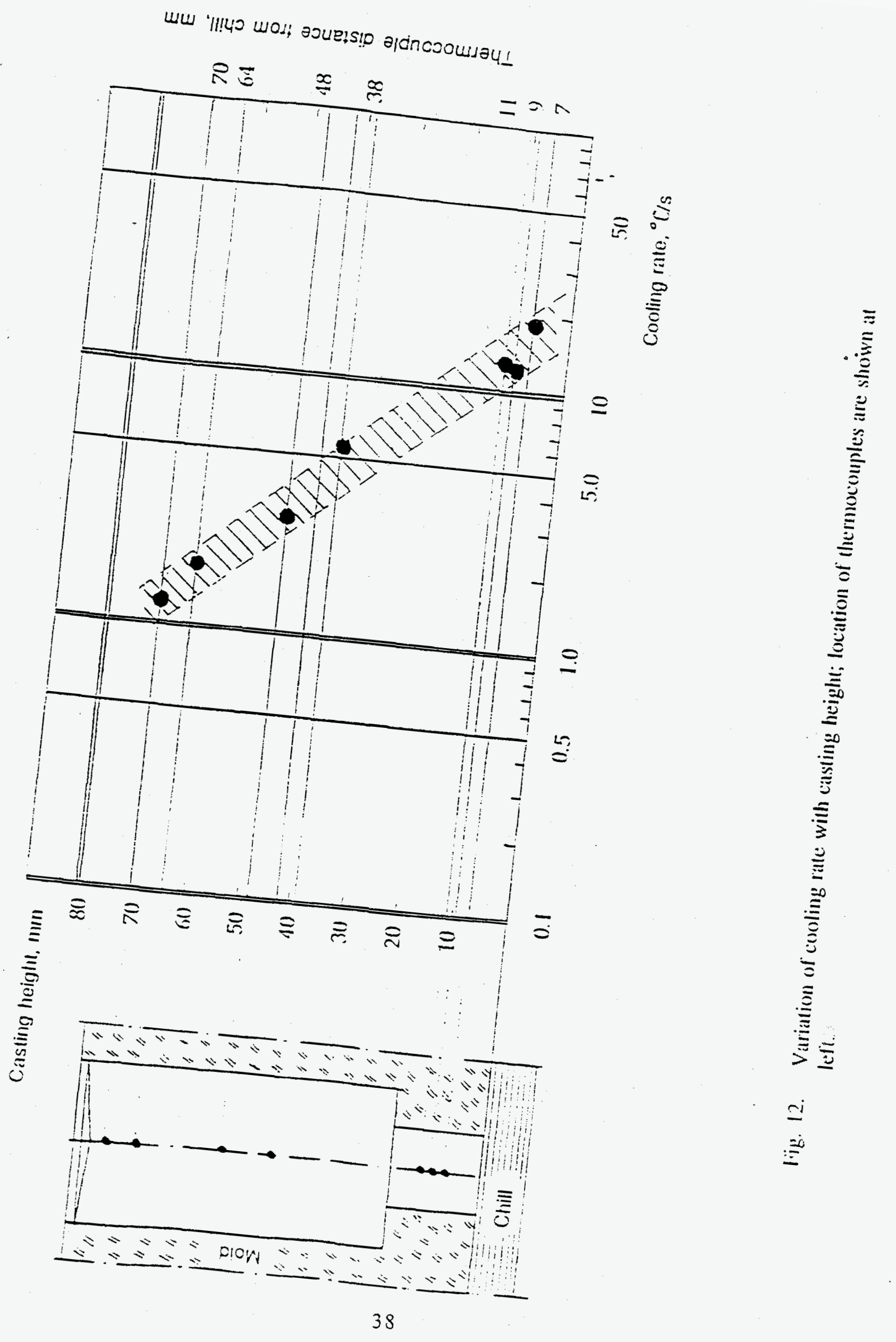


dol (3) มppp!u (q) uonoq (e)

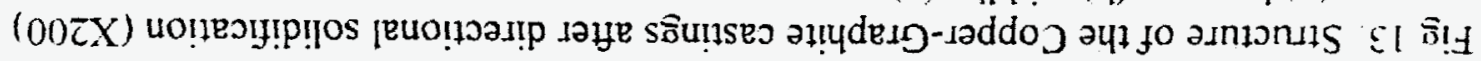

(q)

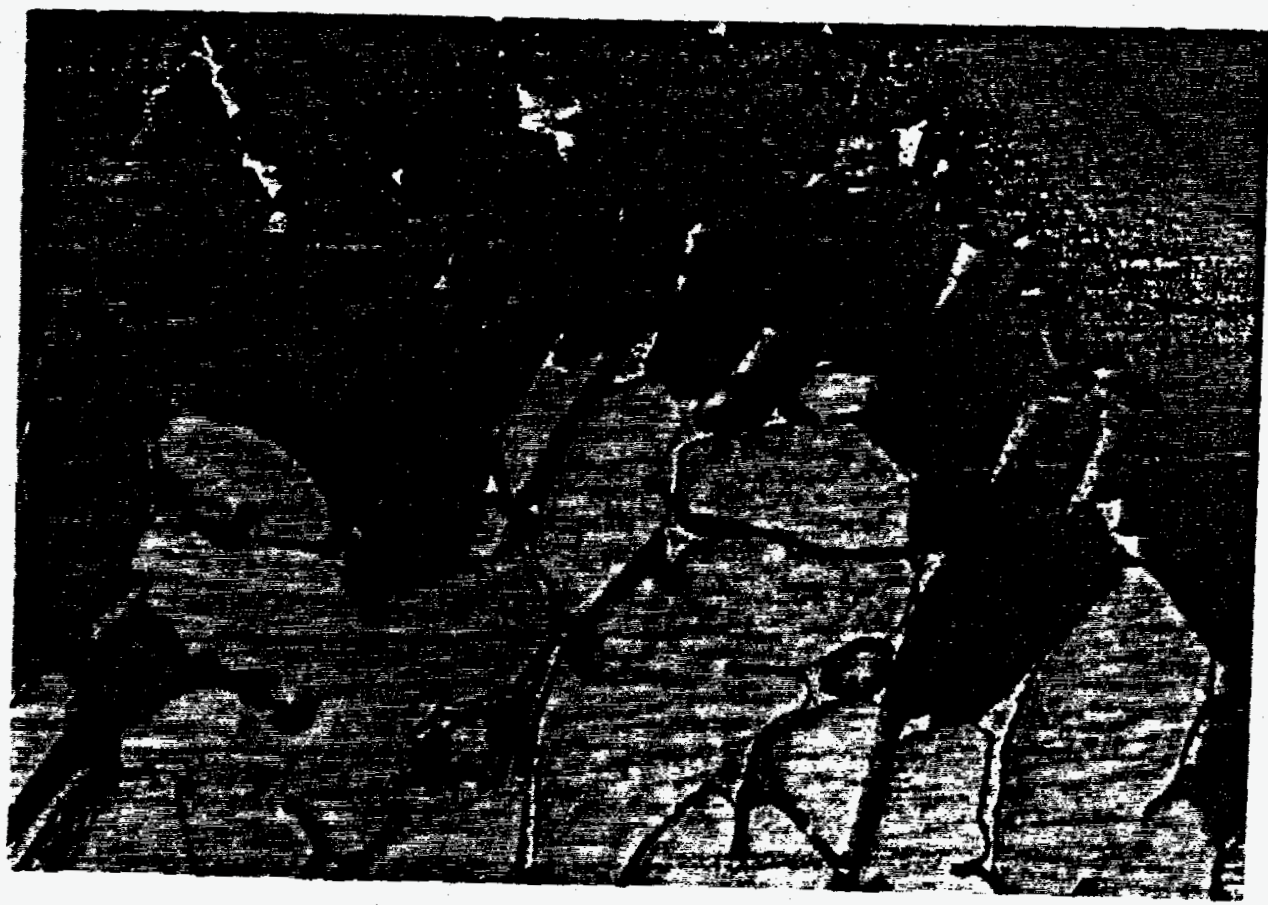

(B)

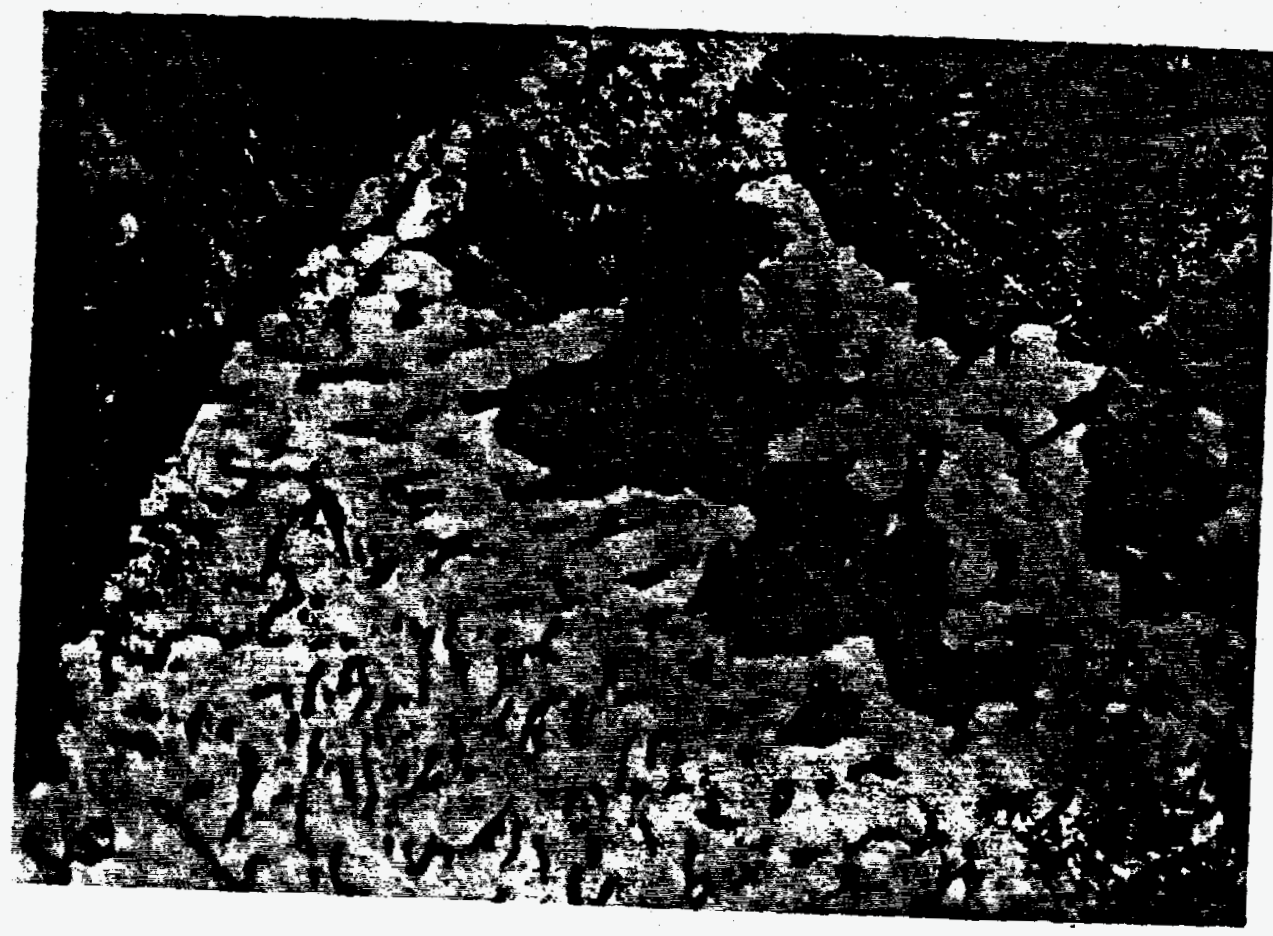




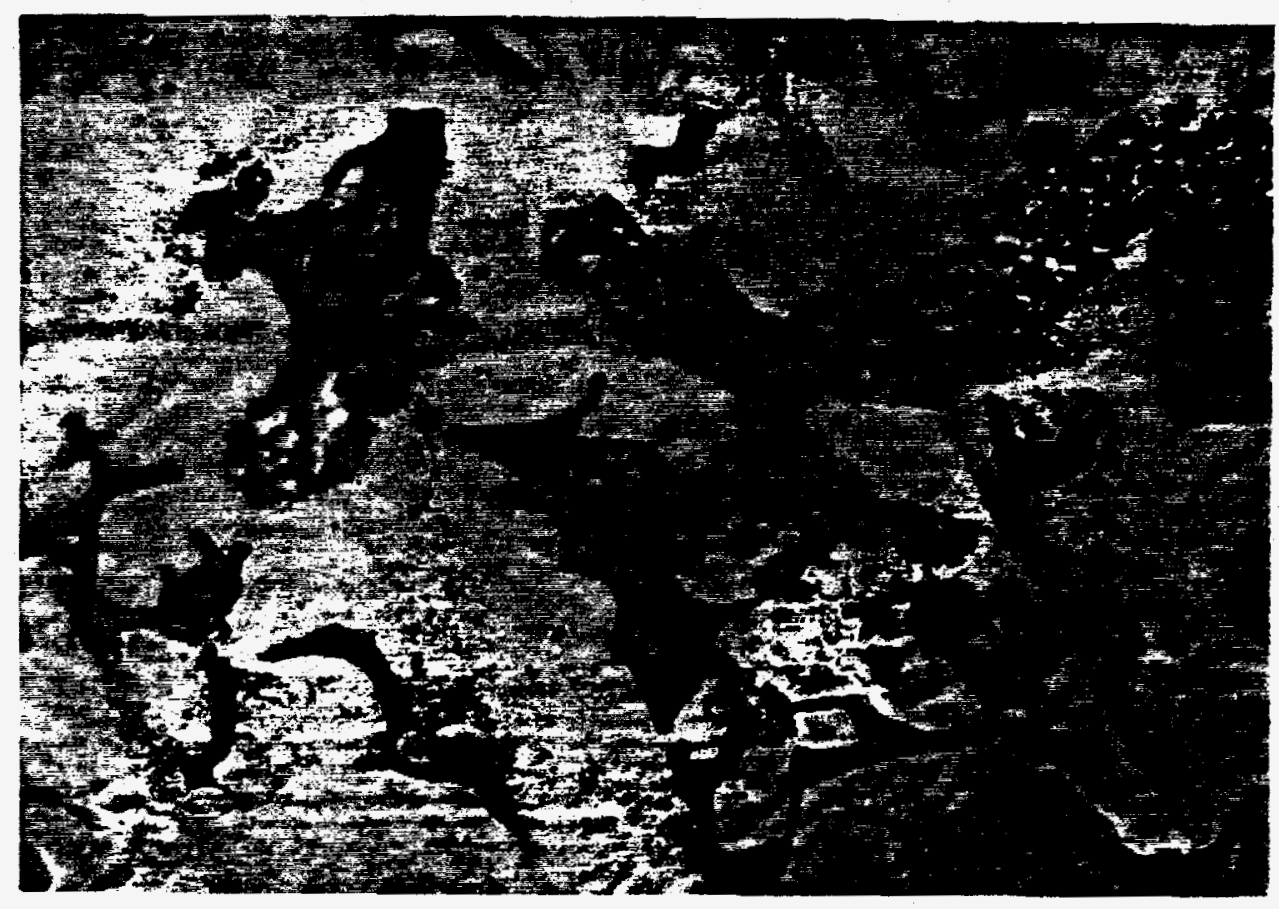

(c)

Fig 13. Structure of the copper-graphite castings after directional solidification(X200) (a) bottom (b) middle (c) top 


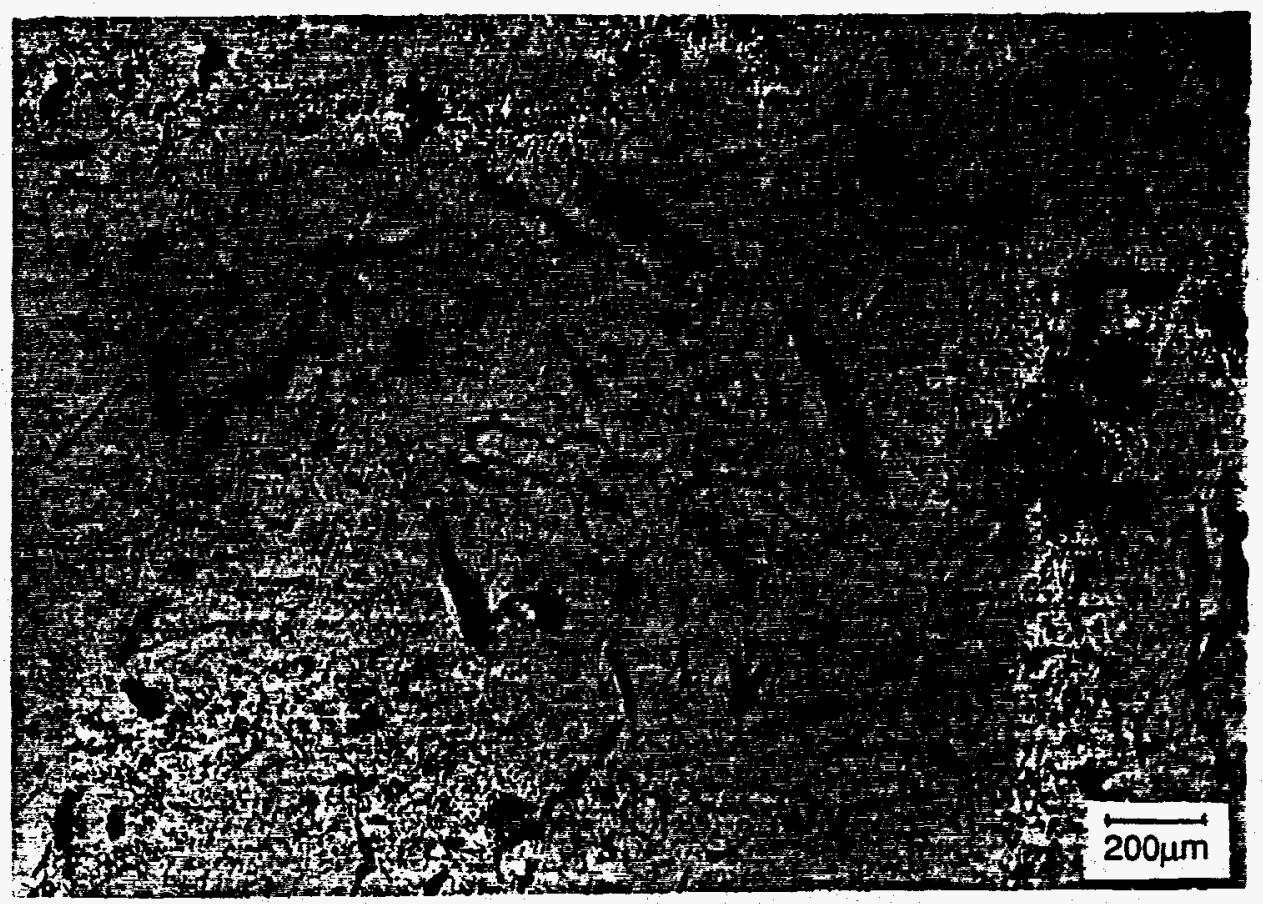

(a) position \#1, end (see Fig.8)

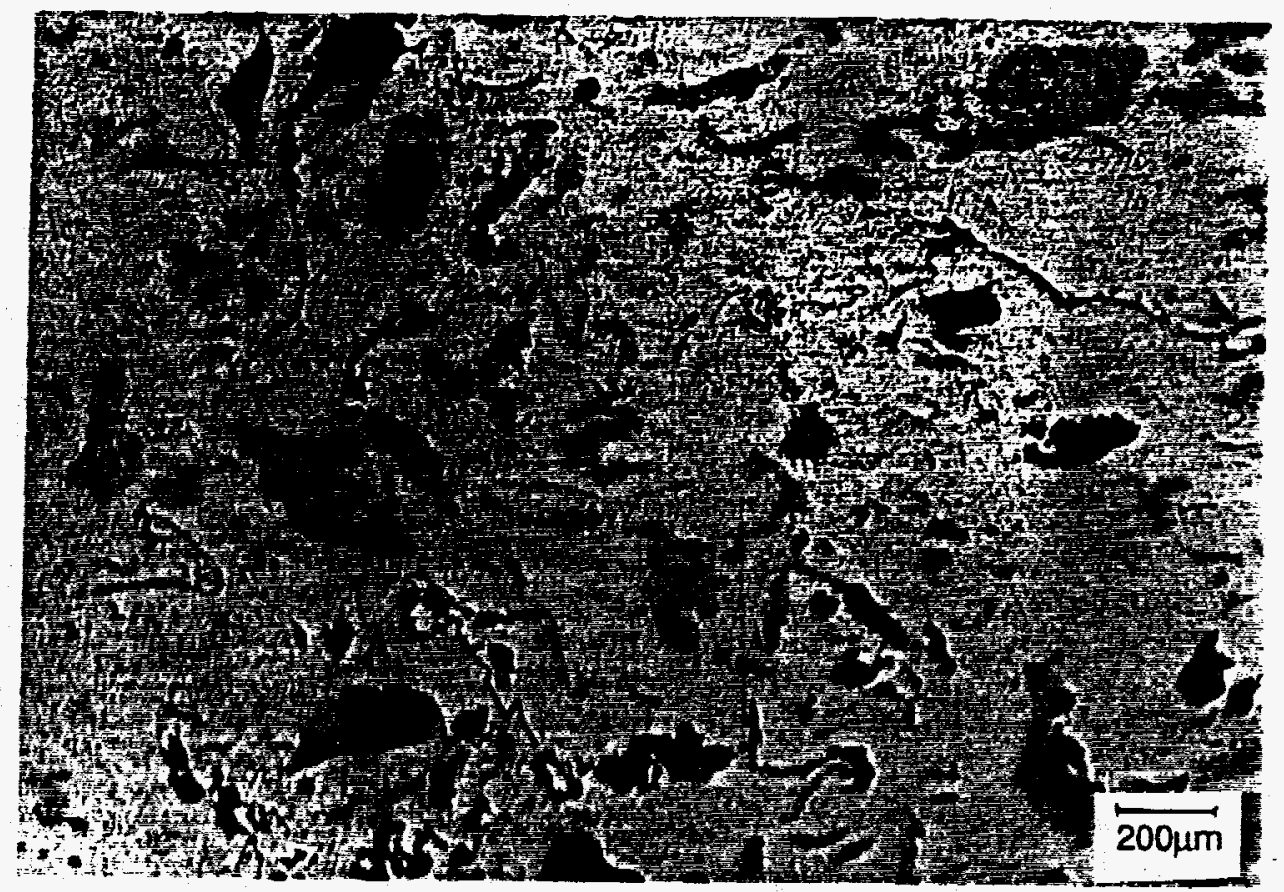

(b) position \#6, entrance (see Fig.8)

Fig 14. Photomicrographs of fluidity spiral of yellow brass-1.5 wt\% graphite, $1 \mathrm{wt} \% \mathrm{Ti}$ composite, showing distribution of graphite. 


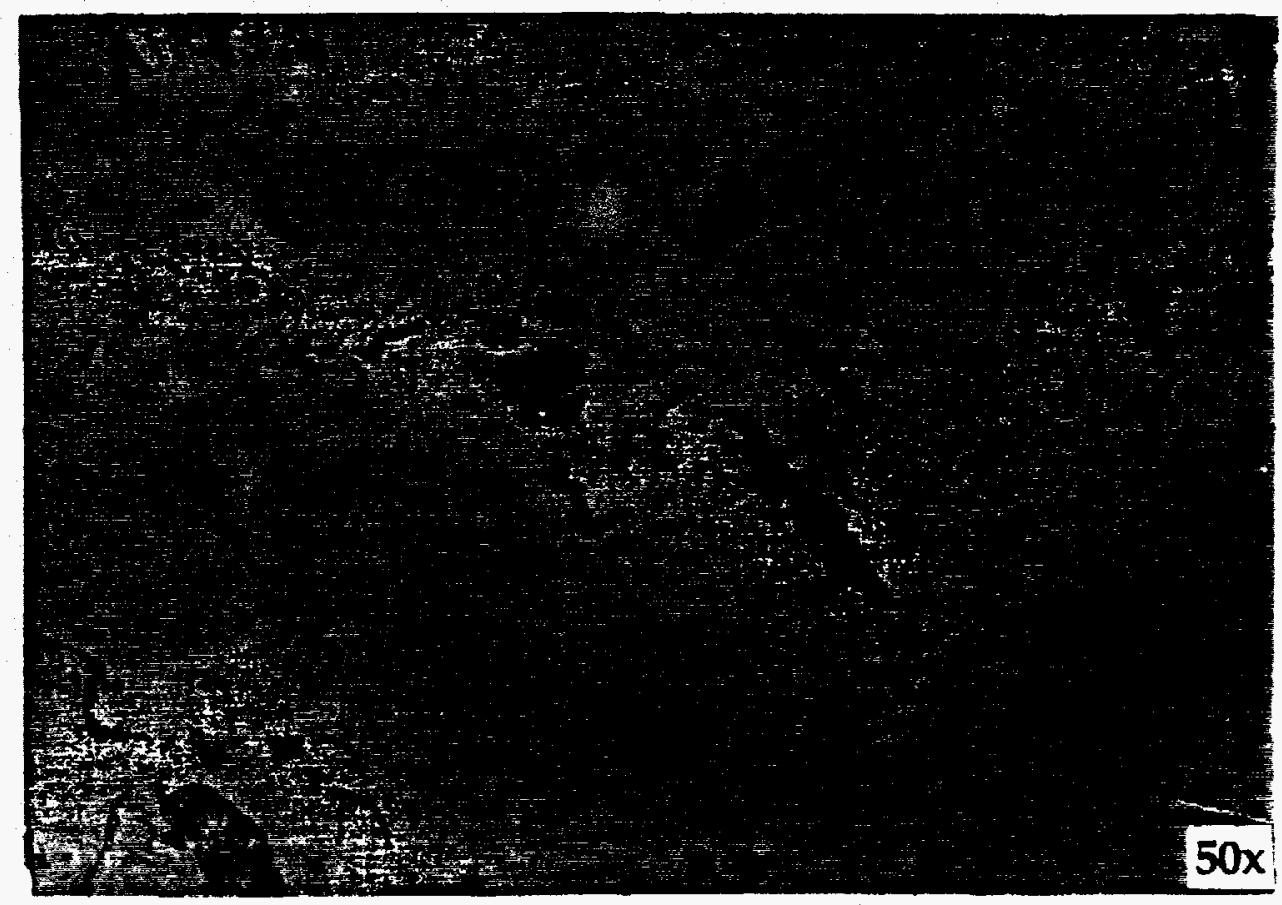

(a) position \#3

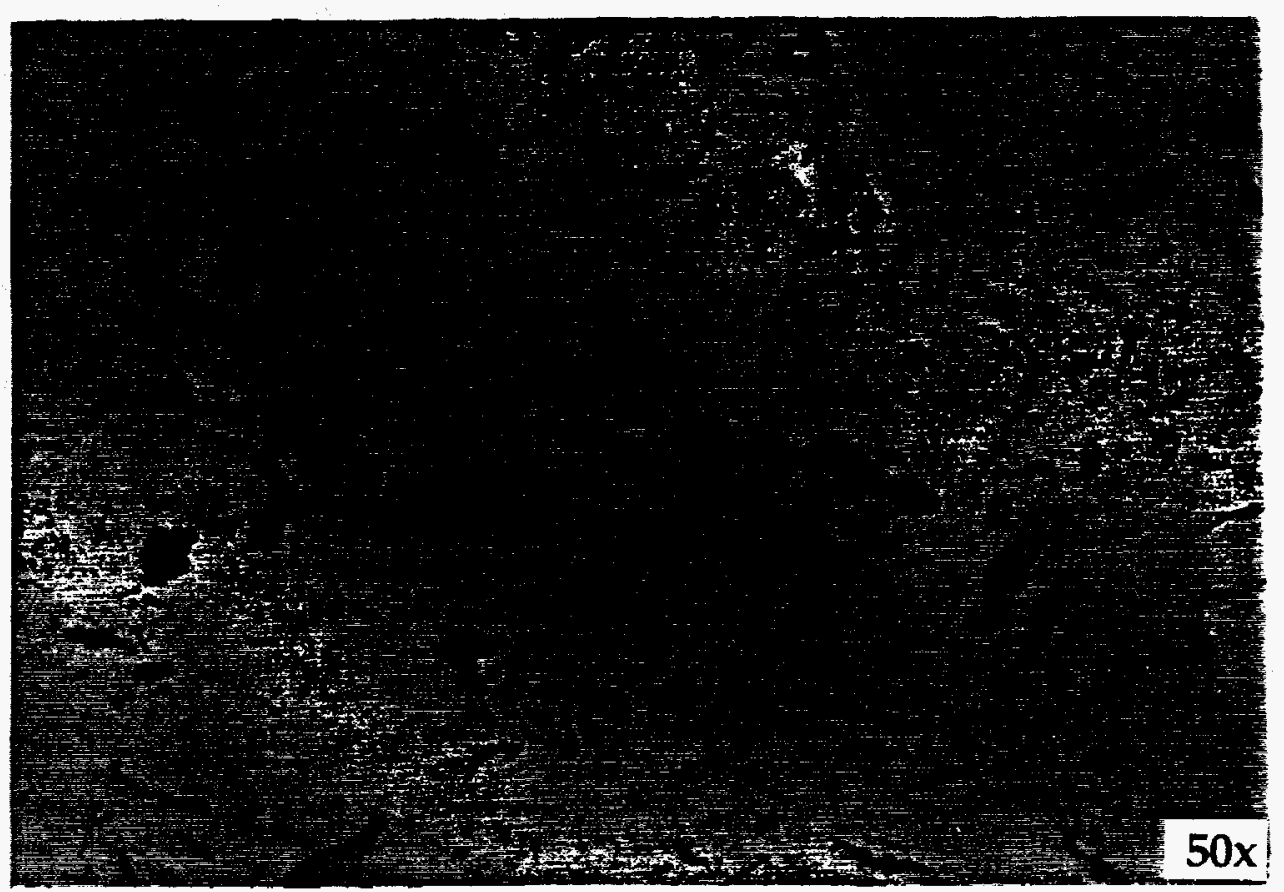

(b) position \#4

Fig 15. Photomicrographs of fluidity spiral of yellow brass-1.5 wt\% graphite, 1 wt $\% \mathrm{Ti}$ composite, showing distribution of graphite. 


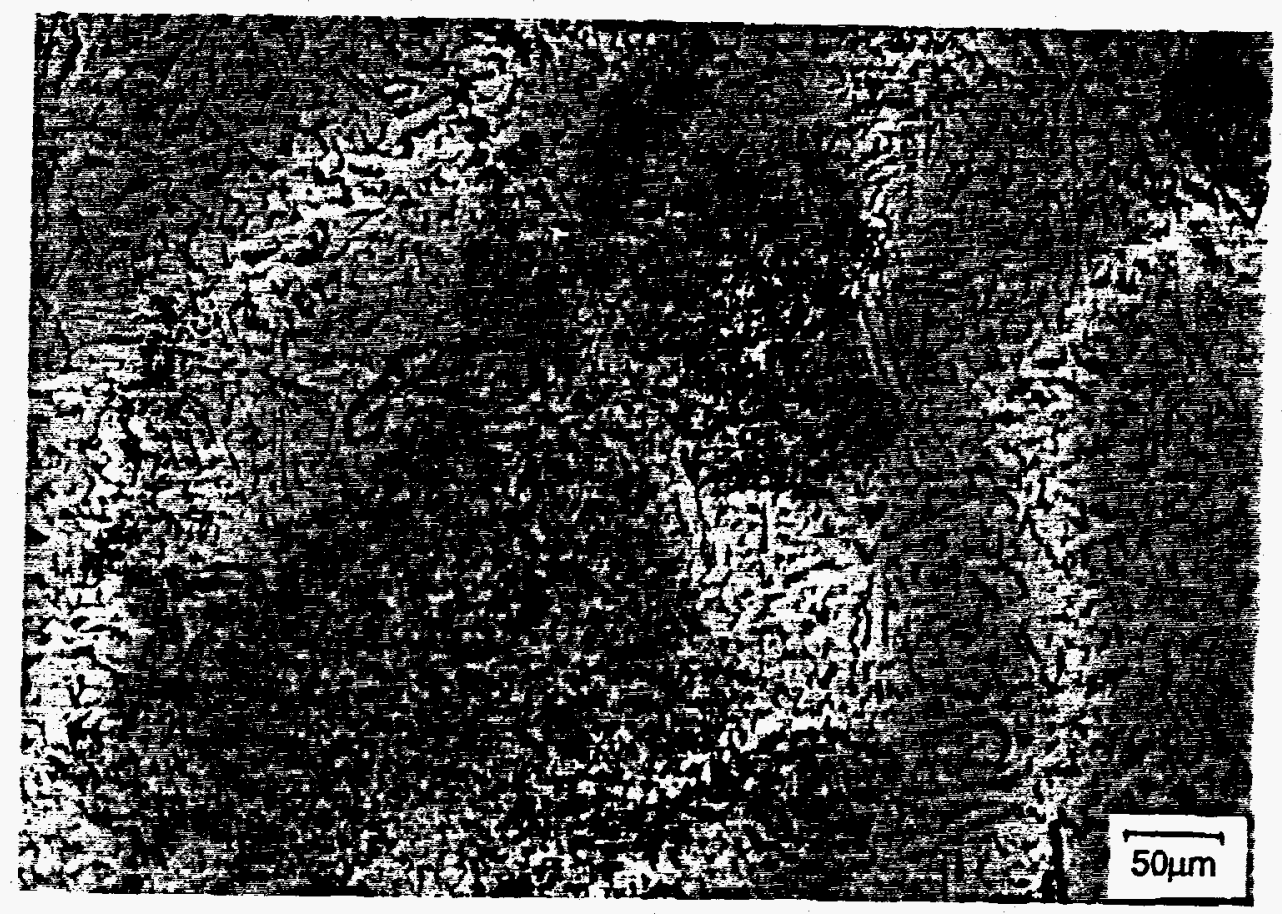

(a) position \#1, end (see Fig.8)

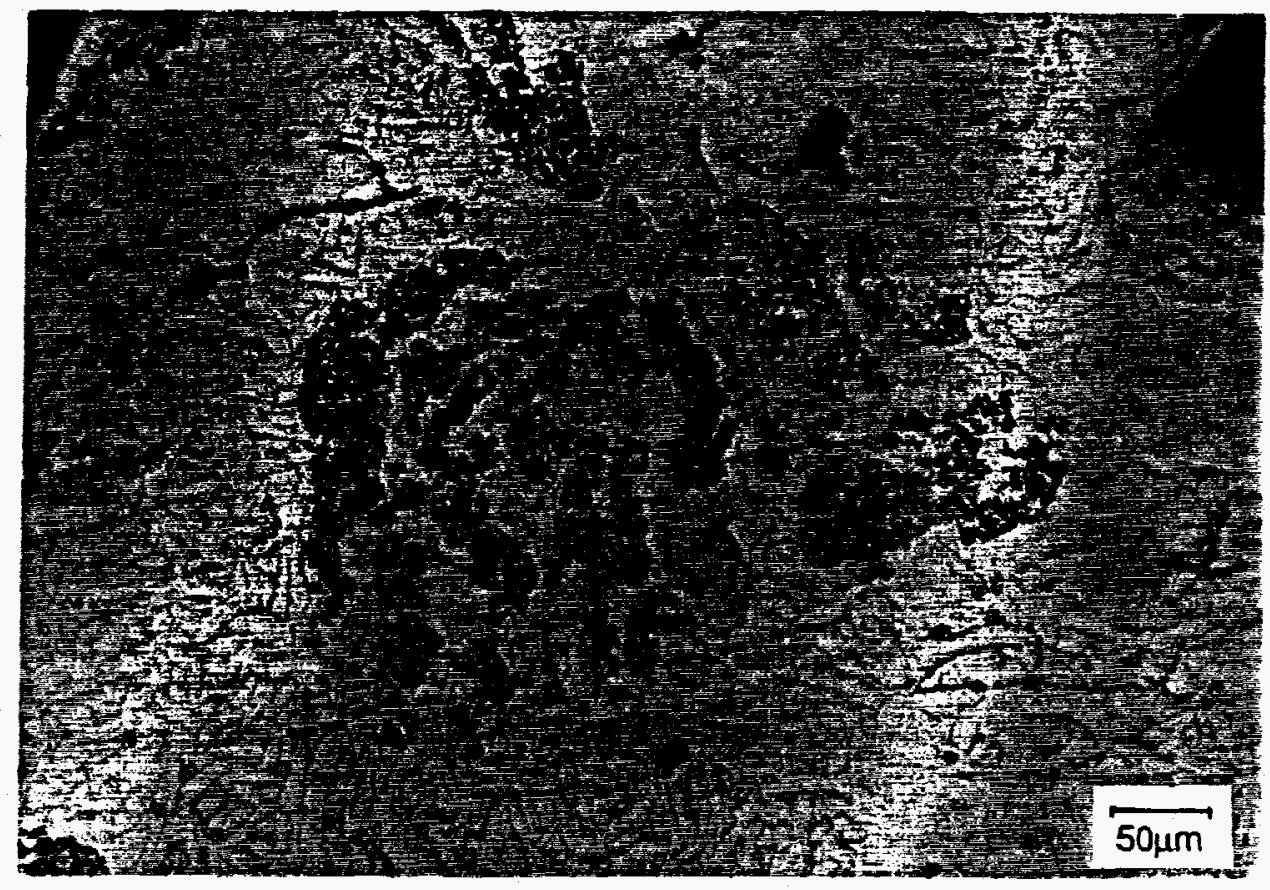

(b) position \#6, entrance (see Fig.8)

Fig 16. Photomicrographs of fluidity spiral of yellow brass-1.5 wt\% graphite, $1 \mathrm{wt} \% \mathrm{Ti}$ composite, showing distribution of graphite, and titanium carbide phase around graphite particles. 


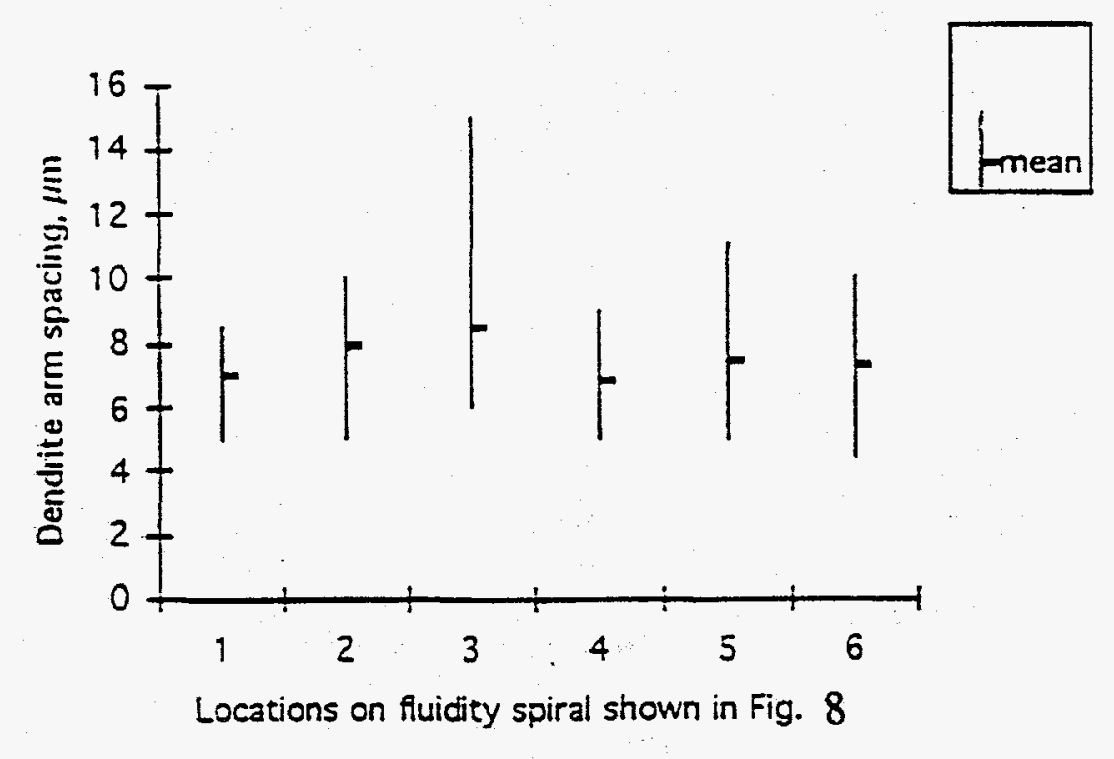

$y_{1}$

Fig 17. Variation of dendrite arm spacing of yellow brass matrix at different locations of casting fluidity spiral copper-graphite alloys. 


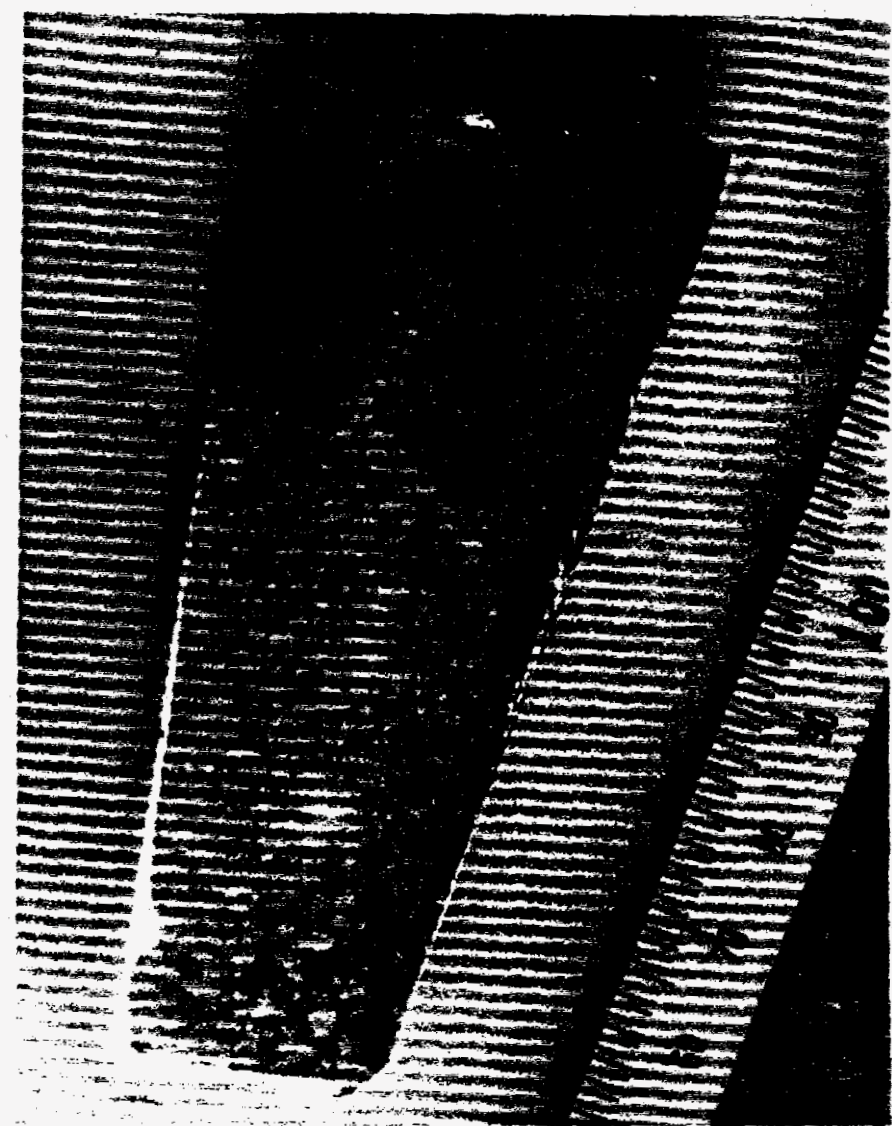

Fig 18. Macrograph at the copper alloy-graphite castings without any isothermal holding at $1000 \mathrm{C}$ (i.e., zero holding time) 


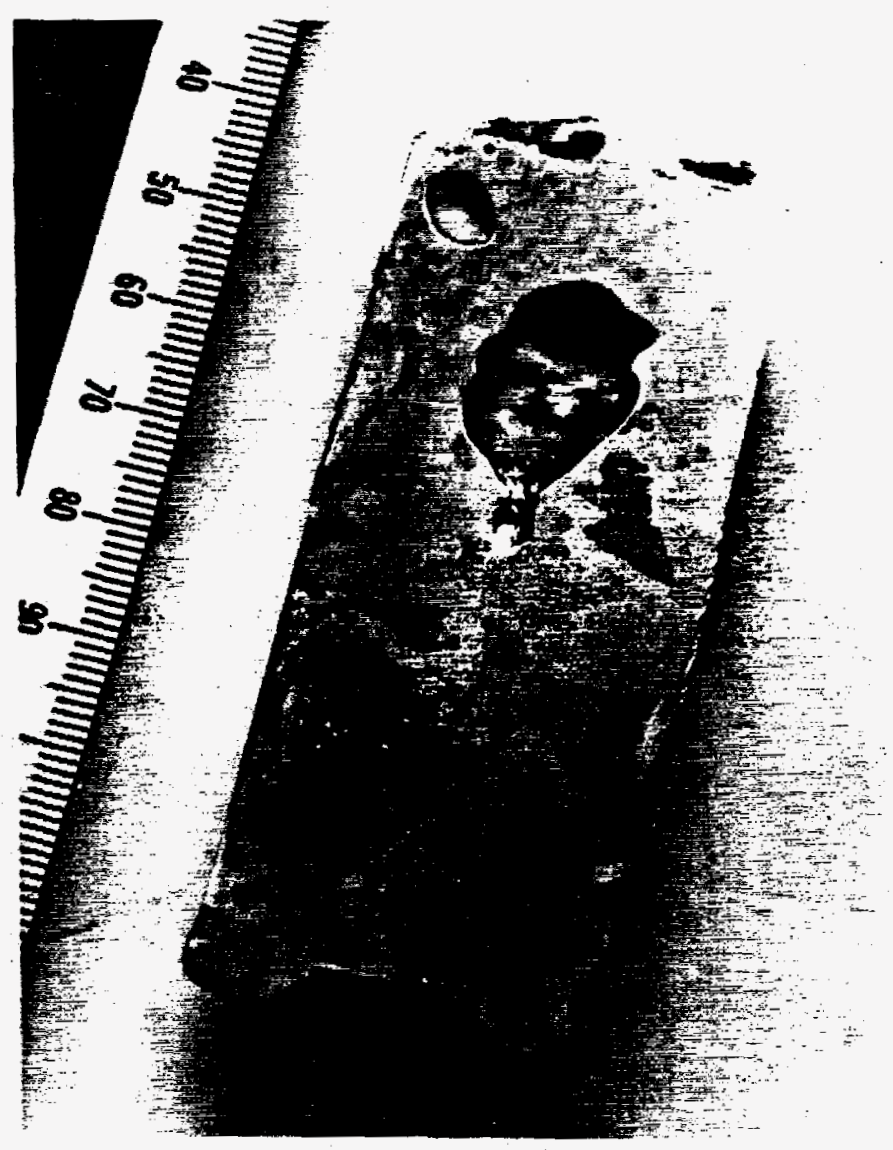

Fig 19. Macrograph of the copper alloy-graphite casting after 10 minutes of isothermal holding at $1000 \mathrm{C}$. 


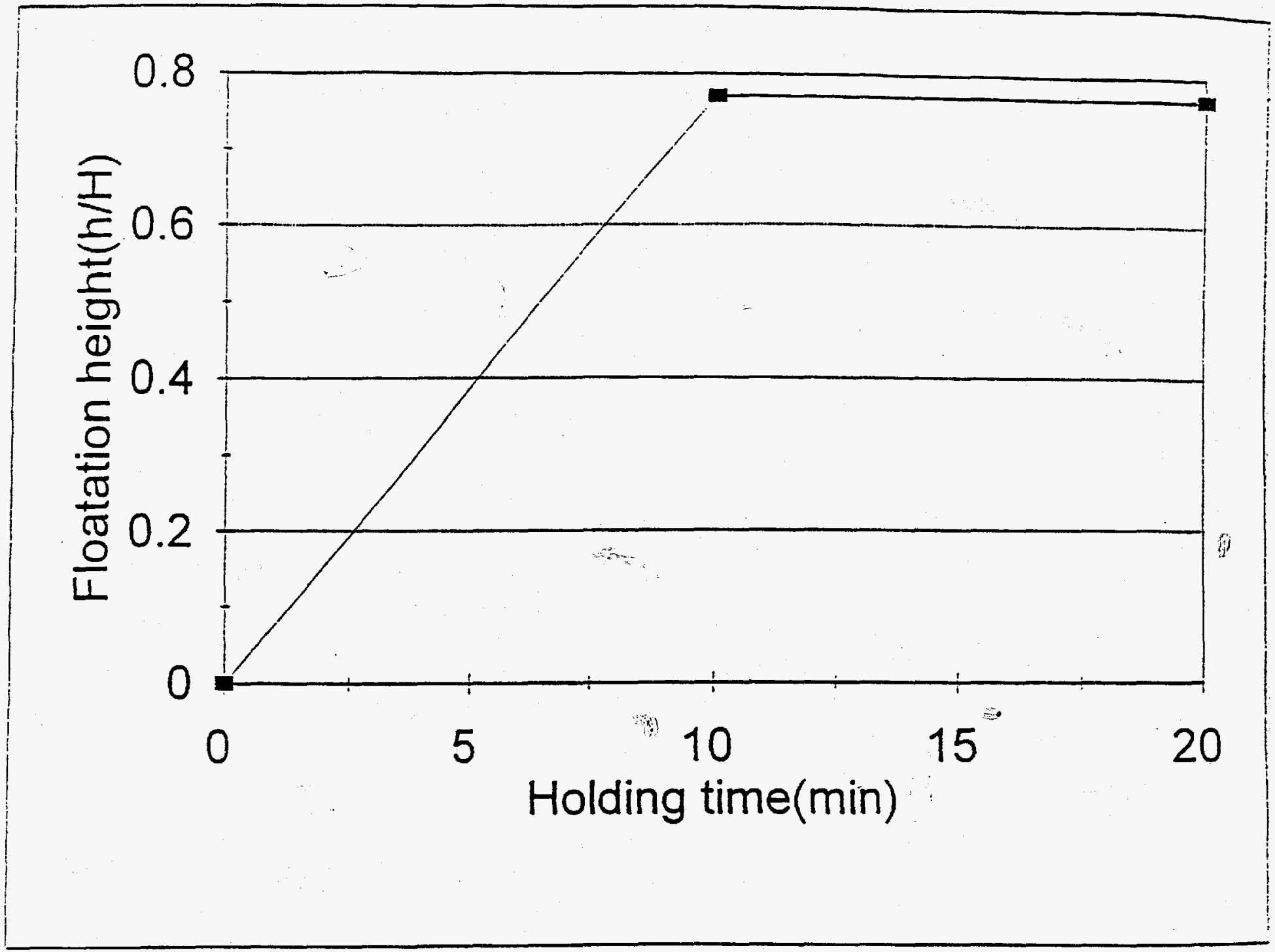

Fig 20. The relative floatation height in the yellow brass-graphite composite as a function of composite-melt holding time 